\title{
Computer-Simulated 3D Virtual Environments in Collaborative Learning and Training: Meta-Review, Refinement, and Roadmap
}

\author{
António Correia, Benjamim Fonseca, Hugo Paredes, Paulo Martins, \\ and Leonel Morgado
}

\section{Introduction}

In recent years, 3D3C worlds have been mentioned in literature as viable platforms for e-learning and distance education (Callaghan et al., 2009), with expectations of a large and increasing impact on teaching and learning in higher education for the near future (Hew \& Cheung, 2010). This is particularly manifested by the institutional adoption of Second Life and OpenSimulator, as well as the more sporadic use of other platforms such as World of Warcraft for educational activities (e.g., language teaching). The perceived benefits of their visual immersive components in the context of students' learning range from an augmented sense of reality (Anstadt et al., 2013) to the enhanced spatial knowledge representation, increased intrinsic motivation and engagement, improved transfer of knowledge and skills to real situations through contextualization of learning, and richer collaborative learning than is possible with 2D alternatives (Dalgarno \& Lee, 2010). Immersive multiuser virtual worlds have been recently adopted as cost-effective solutions for creating simulations in a vast set of application areas, including space exploration, virtual laboratories, healthcare and emergency response, cultural heritage and

\author{
A. Correia $(\bowtie)$ \\ University of Trás-os-Montes e Alto Douro, UTAD, Vila Real, Portugal \\ e-mail: ajcorreia1987@gmail.com \\ B. Fonseca $\bullet$ H. Paredes $\bullet$ P. Martins \\ University of Trás-os-Montes e Alto Douro, UTAD, Vila Real, Portugal \\ INESC TEC, Porto, Portugal \\ e-mail: benjaf@utad.pt; hparedes@utad.pt; pmartins@utad.pt \\ L. Morgado \\ INESC TEC, Porto, Portugal \\ Universidade Aberta, Lisbon, Portugal \\ e-mail: leonel.morgado@uab.pt
}


archaeology, military training, engineering, urban planning, and economics (Jarmon et al., 2009; Allison et al., 2012). These hybrid virtual ecosystems provide an experience which transcends cultural, social, language, distance, and temporal barriers through different modes of interaction (Anstadt et al., 2011), allowing a way to creatively explore critical thinking (Phillips \& Berge, 2009) while supporting collaborative learning strategies and activities within which every learner agent plays an essential role. Although many studies have shown the interest of students in immersive multi-user virtual worlds, the full potential of the use of various kinds of $3 \mathrm{D} 3 \mathrm{C}$ worlds for teaching and learning is still to be realized (Dalgarno \& Lee, 2010; Allison et al., 2011; Duncan et al., 2012).

This chapter extends and allows the refinement of Correia et al.'s (2014) metaanalysis on the current challenges and opportunities of simulated environments for education and training. "Computer-based Simulated Environments: From Technology to Social Engineering" presents some background on virtual worlds with emphasis on its history and applicability. "The Unrealized Potential of Virtual Worlds for Teaching and Learning: Meta-Analysis" introduces the method and the sample dimensions concerning the metadata extracted, and "Discussion" discusses their implications in the form of theoretical framework. Finally, some concluding remarks are provided in "Final Thoughts."

\section{Computer-Based Simulated Environments: From Technology to Social Engineering}

Historically, visual multi-user virtual worlds have been around since the late 1980s, and some even before as "hardware-only systems" (Joslin et al., 2004), incorporating technical improvements such as simulators, stereoscope, 'cinerama', headmounted displays, and trackers (Grady, 1998). Text-based and 2D perspective virtual environments date from even earlier in the form of systems such as textbased multi-user virtual worlds or Multi-User Dungeons (MUD) and similar MUD-inspired systems (Bartle, 2010). The first known studies reporting results of educational practices with virtual worlds in the form of MUD were presented in the 1990s. Such studies mentioned aspects related with changes in educational dynamics, students' and teachers' behavior, online identities, technological issues, and pragmatic concerns on the management of these platforms (Haynes \& Holmevik, 1998). Other topics studied in the first decades included location and time dependencies, reality vs. virtuality, anonymity vs. true identity, human vs. technological factors, level and scale of immersion, play vs. work, and presence vs. telepresence. In this sense, Jäkälä and Pekkola (2007) argued that the research efforts on virtual worlds have transited "from considering them as tools to examining their use, from technology engineering to social engineering". While the focus relapsed on the technological aspects of 3D3C worlds, there has been a need for understanding social interaction, comparing the magnitude of co-presence (Bailenson \& Yee, 
2008). A key purpose of "social virtual worlds" relies on the co-construction of a shared meaning through object handling and communication between different people within a world (Damer, 2008). Stangl et al. (2012) summarizes success factors from scientific studies, pointing the support for a critical mass of residents as one of the several success factors attracting users.

Inter-user, avatar-mediated communication is essential for an understanding of the potential of virtual worlds for learning and training (Morgado et al., 2010). 3D3C worlds can be understood as immersive virtual worlds within which people can interact with software agents "using the metaphor of the real-world but without its physical limitations" (Davis et al., 2009). Furthermore, Ghanbarzadeh and colleagues (2014) define a three-dimensional virtual world as "a computersimulated electronic 3D virtual environment that users can explore, inhabit, communicate, and interact with via avatars, which are graphical representations of the users". Such simulated environments can also be described as 3D spaces populated by avatars which support collaborative learning, work and social play (Benford et al., 2001; Duncan et al., 2012) or more generically as multi-user spatial environments within which the interaction paradigm is that of user-embodied avatars, regardless of the visual representation (e.g., the 3D space may be described via 2D perspectives or in textual form, as stressed by Morgado et al., 2010). Synoptically, 3D3C worlds can be seen as collaboration ecosystems that minimize the risk of complex tasks through simulation abilities. According to Bentley et al. (1992), such technology "may support some aspects of social interaction not readily accommodated by technologies such as audio-and video-conferencing and shared desktop applications", encouraging peripheral awareness in processes such as content sharing and artifact production.

The development of digital ecologies has been marked by media spaces, virtual worlds, mixed reality, and hybrid ecologies that merge the mixed reality with ubiquitous computing "to bridge the physical-digital divide" (Crabtree \& Rodden, 2008). A computer-based simulated environment provides several features for creating an online presence that can replicate real-world scenarios in multi-user settings. Such environments enable social interaction through several communication channels (e.g., text, audio, graphical icons, visual gestures, and multisensory inputs). They also support coordination actions, and allow cooperation settings by using shared applications to track changes and manipulate (or interact with) digital artifacts for which team members can jointly look at (Schroeder et al., 2006; Jarmon et al., 2009). Immersive realism, interoperability, scalability, and ubiquity of access and identity are considered critical elements of a viable 3D3C world, and more research is needed "to provide context for considering the present state and potential future of 3D virtual spaces" (Dionisio \& Gilbert, 2013). From text-based virtual worlds to the open development of metaverse platforms (e.g., Open Source Metaverse), collaborative learning has been a topic which requires a clear focus.

Earlier studies on collaboration dynamics using 3D3C worlds identified potential features for enhancing peripheral awareness (Bentley et al., 1992). Recently, research suggests that computer-based simulated environments can be well-suited for experiential learning activities (Jarmon et al., 2009), organizational learning 
(Dodgson et al., 2013), business simulations (Mak \& Palia, 2014), information systems auditing (Moscato \& Boekman, 2014), and game-based learning (Sung \& Hwang, 2013). Furthermore, healthcare approaches such as dentistry (Phillips \& Berge, 2009), medical learning (Wiecha et al., 2010), cardiopulmonary resuscitation (Creutzfeldt et al., 2010), stress inoculation training (Serino et al., 2014), and healthy aging (Paredes et al., 2014; Siriaraya et al., 2014) have also been supported. Other application areas include virtual tourism (Warburton, 2009), archaeology (Sequeira et al., 2014), aerospace engineering design (Okutsu et al., 2013), training processes in the context of mechanical maintenance tasks (Fonseca et al., 2011), and military operations, tactics and strategies requiring sophisticated technologies for preparing troops to real combat scenarios (Pierzchała et al., 2011). Figure 1 presents a collaborative task performed in a computer-simulated 3D virtual environment. As argued by Fonseca et al. (2011), the adoption of a 3D virtual learning environment for training contributes to increase the efficiency of certain phases by enabling trainees to perform simulated activities without the involvement of physical resources.

Regarding the potential of such environments for higher education, researchers have been focused on the identification of requirements and potential benefits of project-based instruction and collaboration. In particular, researchers have found opportunities associated with increased sense of shared presence, social interaction and collaborative learning, partially liquefied social boundaries, and lowered social anxiety. In this context, the Collaborative Learning Environment with Virtual Reality (CLEV-R) was an example of a technical development for enhancing the afore-mentioned aspects (Jarmon et al., 2009). Benefits in the use of simulation tasks in this kind of 3D virtual learning environments range from cost saving to efficiency and security. Furthermore, the strengthening of sociability and scalability (Grimstead et al., 2005) can be far greater comparing with conventional, collaborative multi-user enabling systems.

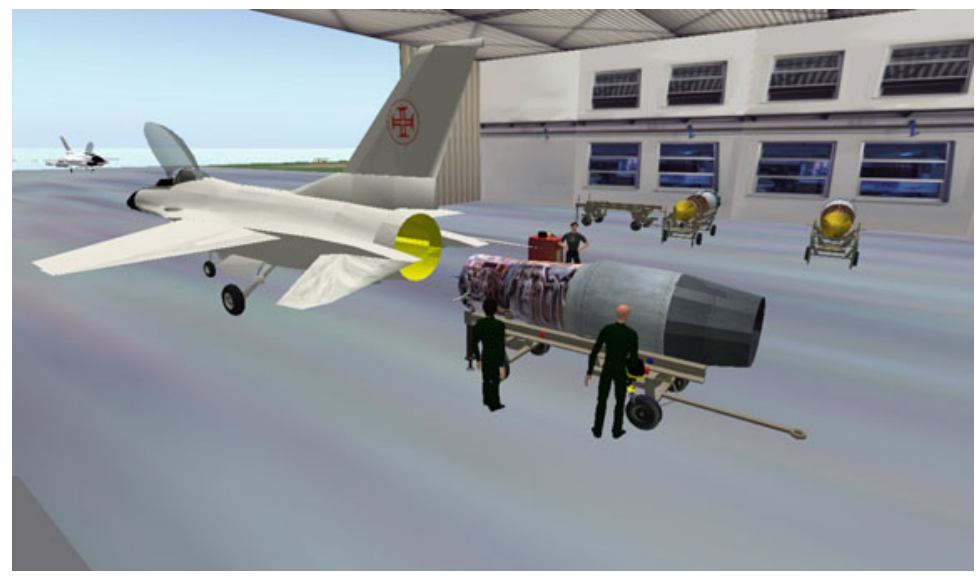

Fig. 1 Collaborative aircraft maintenance process in a 3D virtual learning environment 
Research on K-12 and higher education has suggested that interactions in 3D3C worlds can stimulate users while producing understandings of the main subject matter (Jonassen, 2004). The characteristics of this kind of virtual environment may promote collaboration for making the work more dynamic and engaging (Reeves et al., 2008). 3D3C worlds still have the potential to support crowded online settings where hundreds of participants can reach social engagement by dynamically forming subgroups (Schneider et al., 2012). However, the lack of in-depth studies for evaluating dynamic scenarios constitutes a challenge for identifying requirements in adapting collaboration mechanisms to individuals, groups, and crowds.

\section{The Unrealized Potential of Virtual Worlds for Learning and Training: Meta-Analysis}

\subsection{Method}

The details about the initial sample selection and review processes were presented by Correia et al. (2014), and this chapter extends the previous work by distilling conceptual evidences as meta-theoretic units of analysis. The results of this study were obtained applying a Systematic Literature Review (SLR) process based on the known guidelines (Kitchenham et al., 2009; Stapić et al., 2012). Qualitative content analysis techniques (Graneheim \& Lundman, 2004; Onwuegbuzie et al., 2012) were also used as complementary approaches to extract qualitative evidences from literature. In this study, old publications and bibliometric indicators (e.g., authors' affiliation, and number of citations) were discarded from analysis. The focus relies on distinguishing what needs to be undertaken in the use and deployment of 3D3C worlds for collaborative learning and training.

In the first stage, keywords and related terms were introduced and 156 studies were retrieved in accordance to the total number of citations provided by Google Scholar's citation index. This process was complemented by a snowball sampling approach to identify potential studies from references. In the next phase, three duplicated papers were removed. The lack of quantifiable metadata for two studies was also an exclusion criterion. Subsequently, 102 studies were removed due to the inadequacy of their subjects for a meta-analysis focused on 3D3C worlds and their unsolved gaps. The remaining sample is constituted by a set of 49 publications. From this corpus, a wide range of studies related with learning (e.g., K-12, higher education) was identified.

Limitations and possibilities for research were initially extracted as meaning units (or textual excerpts) from which a condensing technique was used. As explained by Graneheim and Lundman (2004), a meaning unit can be understood "as the constellation of words, sentences or paragraphs containing aspects related to each other through their content and context". A condensed meaning unit is a 
description close to the text, and a category is "a group of content that shares a commonality" (Krippendorff, 1980), including sub-categories at varying levels of abstraction. Creating themes is a way to link the underlying meanings together in categories. A total number of 161 condensed meaning units, 48 categories, 11 sub-categories, and 10 themes were clustered using a method similar to Jacovi et al.'s (2006) methodological approach. A refined, meta-synthesis integrating qualitative evidences from a total of 49 publications (see Table 1) summarizes the raw data extracted by meaning unit, topic/category, and theme.

\subsection{Three-Dimensional Immersive Virtual Learning Environments}

Suggestions for future research on the use of 3D3C worlds in learning as presented by Hew and Cheung (2010) are mainly related with exploiting improvements to previous studies, doing longitudinal studies, exploring the attributes/affordances of virtual worlds, examining sociocultural factors, and studying the use of avatars (e.g., gender analysis). Furthermore, Jarmon and colleagues (2009) claimed attention for virtual world teaching and experimental learning by considering the learning curve and the current limitations in single case studies (e.g., few graduate students from distinct academic disciplines). In the meantime, Duncan et al. (2012) indicated the proposal of finely-grained classification models and surveys, better mechanisms for monitoring student learning, the development of immersion technology (e.g., 3D haptic input equipment), the study of in-world behavior and course design, the transition of in-world skills to the real world, and the inclusion of social, minority or disabled groups. In addition, Dalgarno and Lee (2010) explored the 'learning affordances' of 3D virtual environments (e.g., visual realism), while Barbour and Reeves (2009) stressed unsolved challenges for institutions, including but not limited to high start-up costs, student readiness and retention, accreditation, and universal access. Ultimately, Morgado (2013) summarized a set of current technological challenges faced by educators and organizations on employing virtual worlds in education.

Concerning the empirical research on the educational applicability of virtual reality, a 10-year critical review (Mikropoulos \& Natsis, 2011) suggested the development of more studies incorporating intuitive interactivity and settings that use immersive virtual environments. They also pointed the importance of reporting positive results on users' attitudes and learning outcomes in addition to the characteristics and features of virtual reality (e.g., immersion, and sense of presence). A key challenge discussed by researchers such as Inman et al. (2010) relies on the use and adoption of Second Life in K-12 and higher education, comprising the study of participants' affective domain (e.g., learner attitudes and feelings regarding the use of virtual environments as educational learning environments), learning outcomes, and social interaction (e.g., use of communication features associated with 3D 


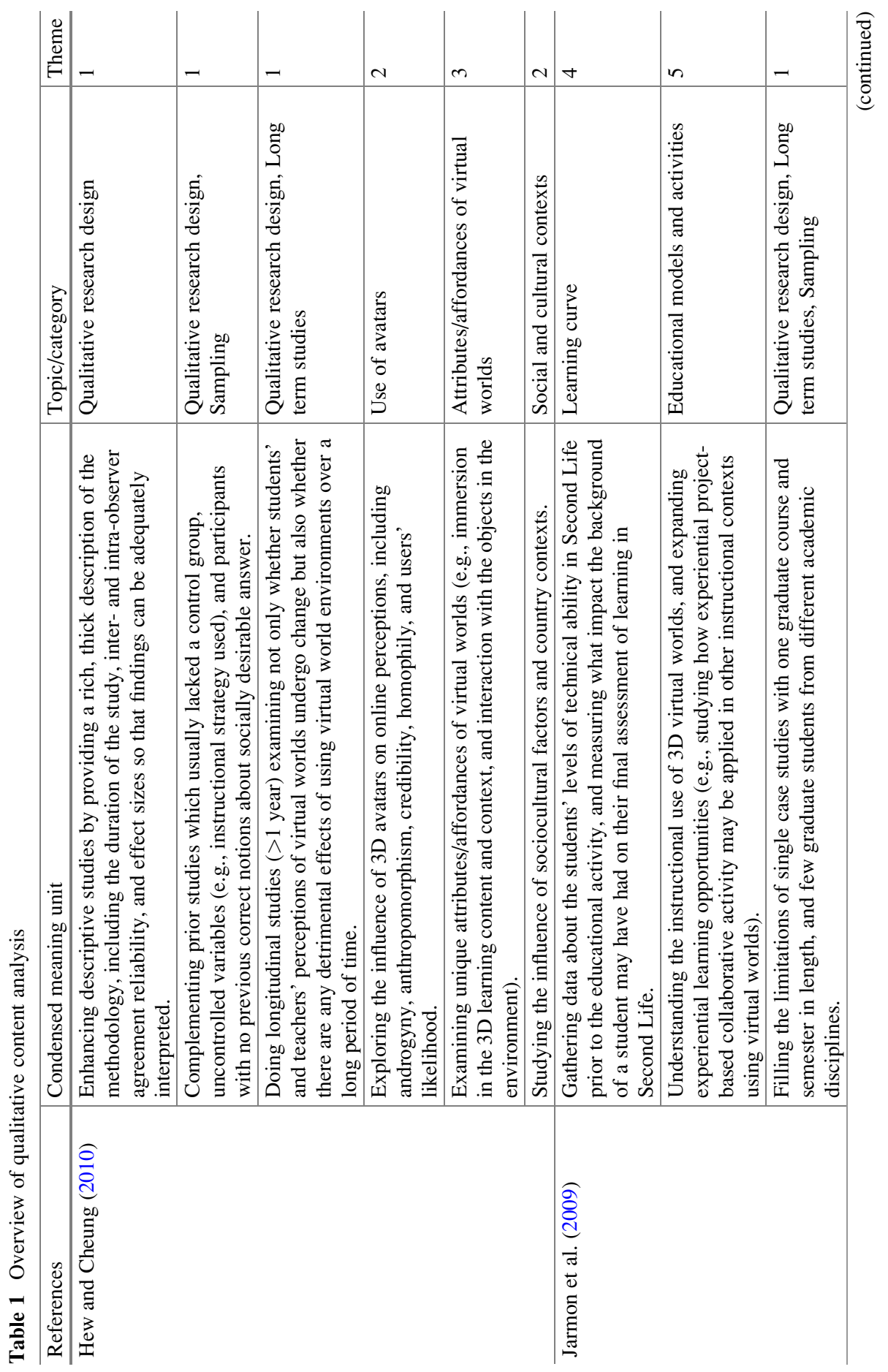




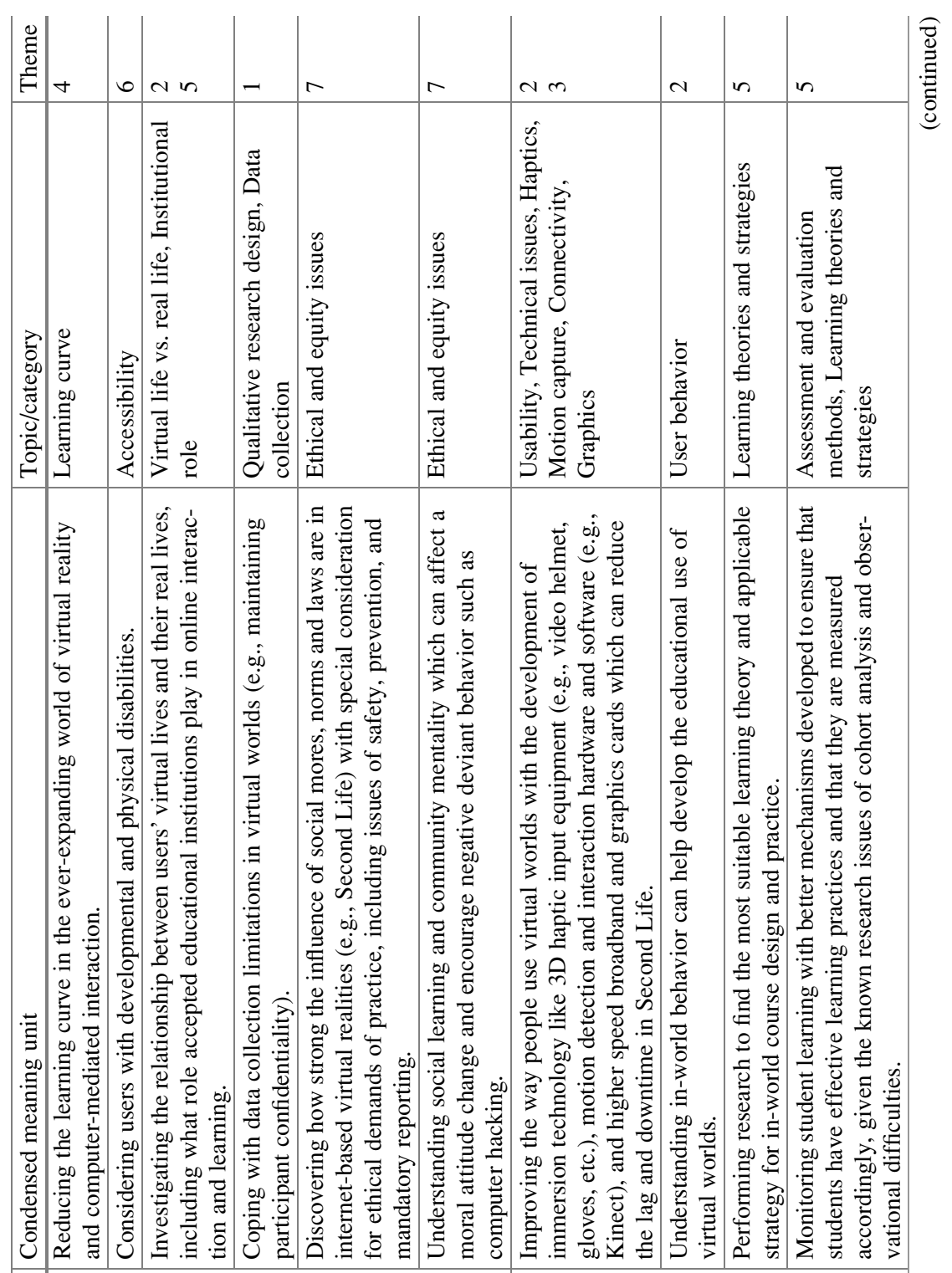

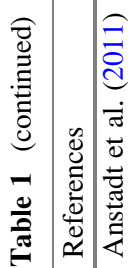

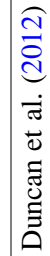




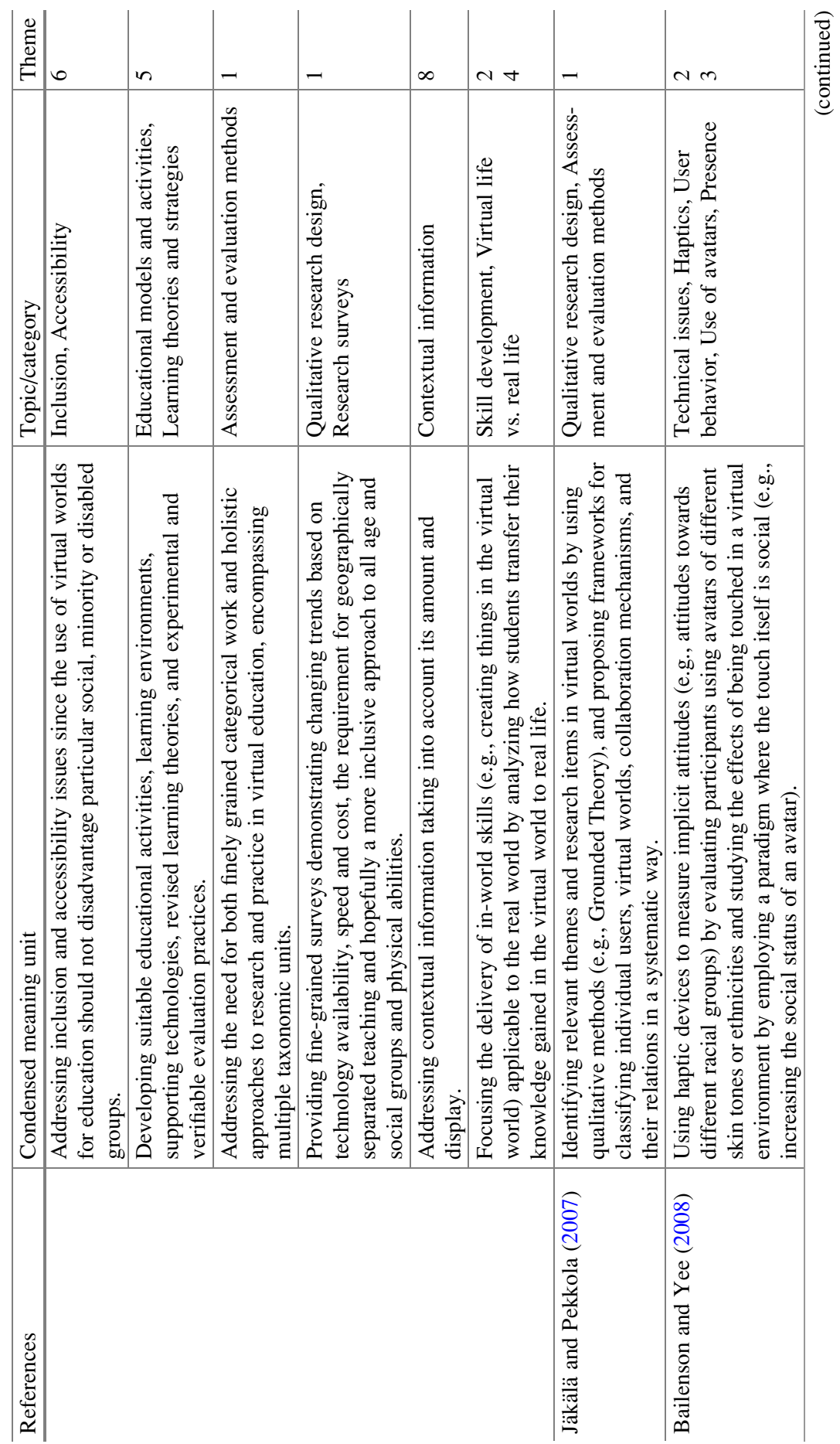




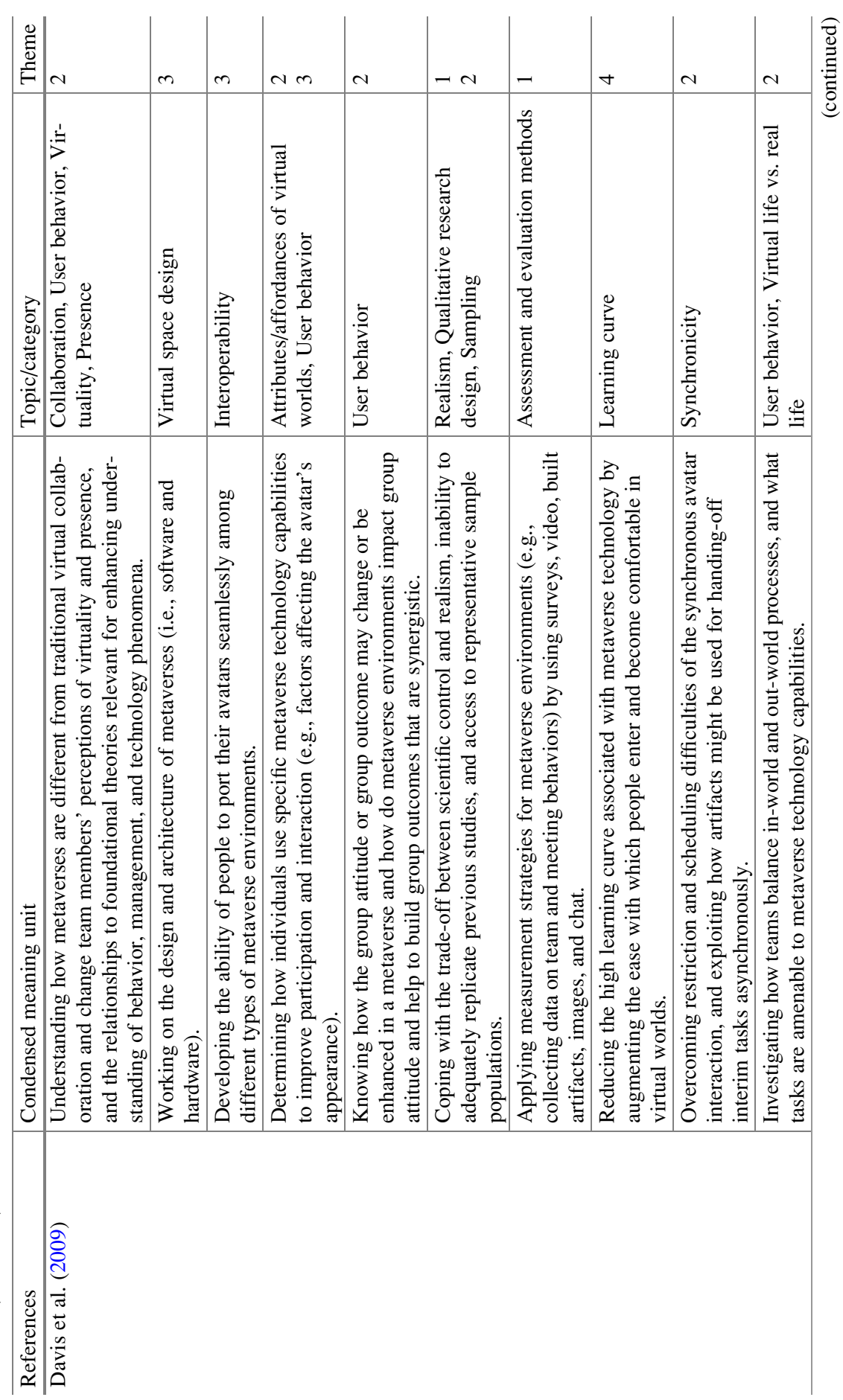




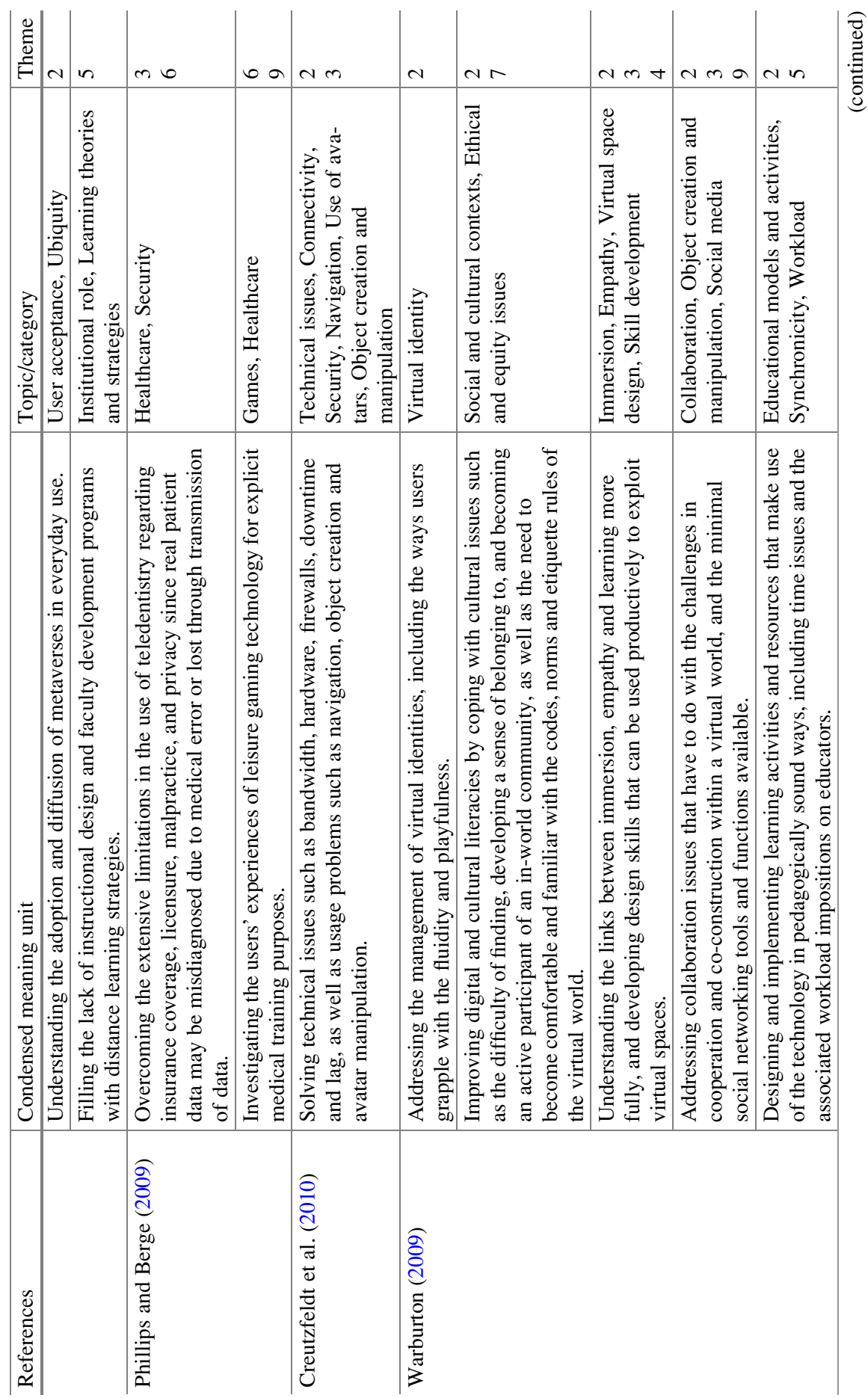




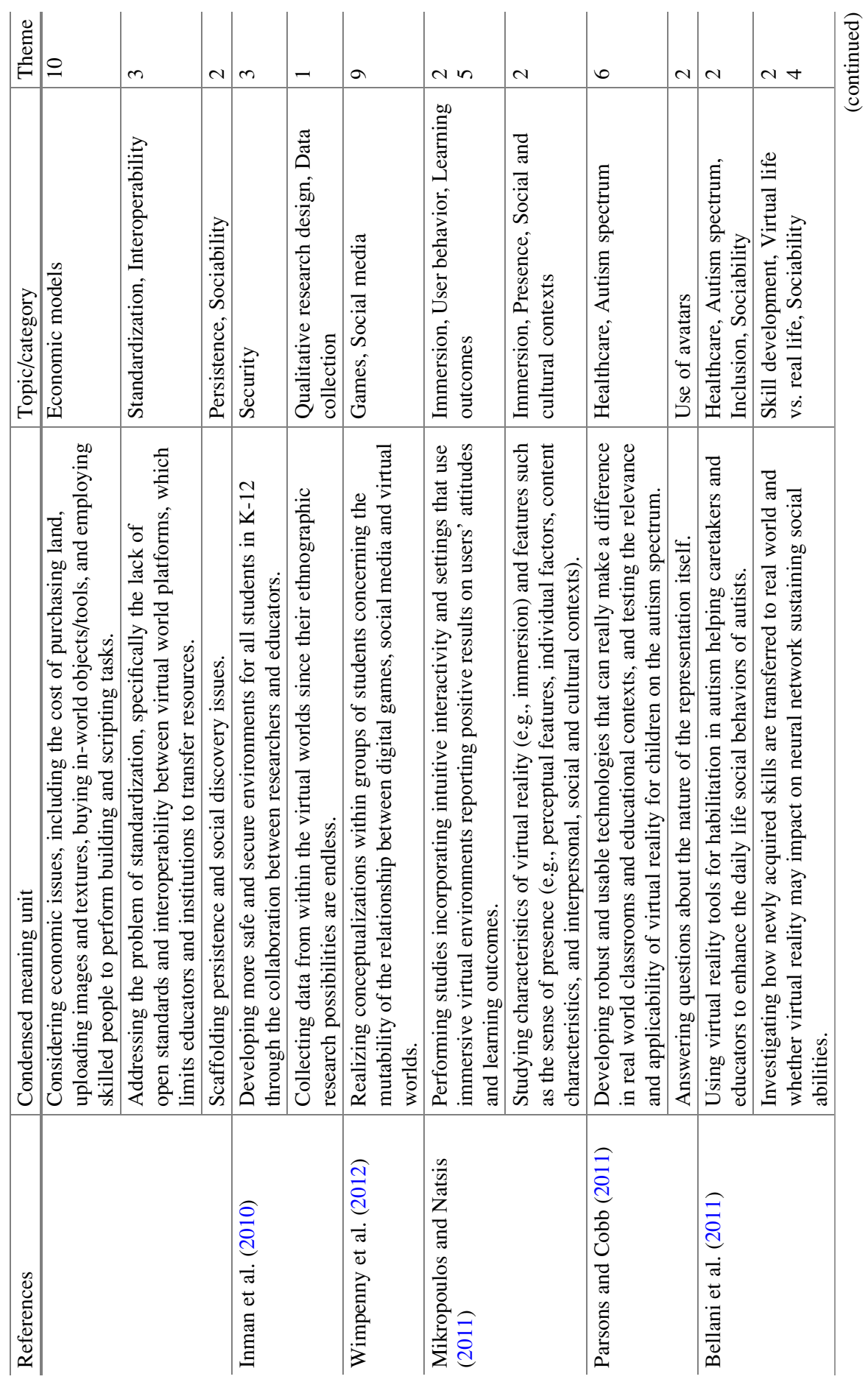




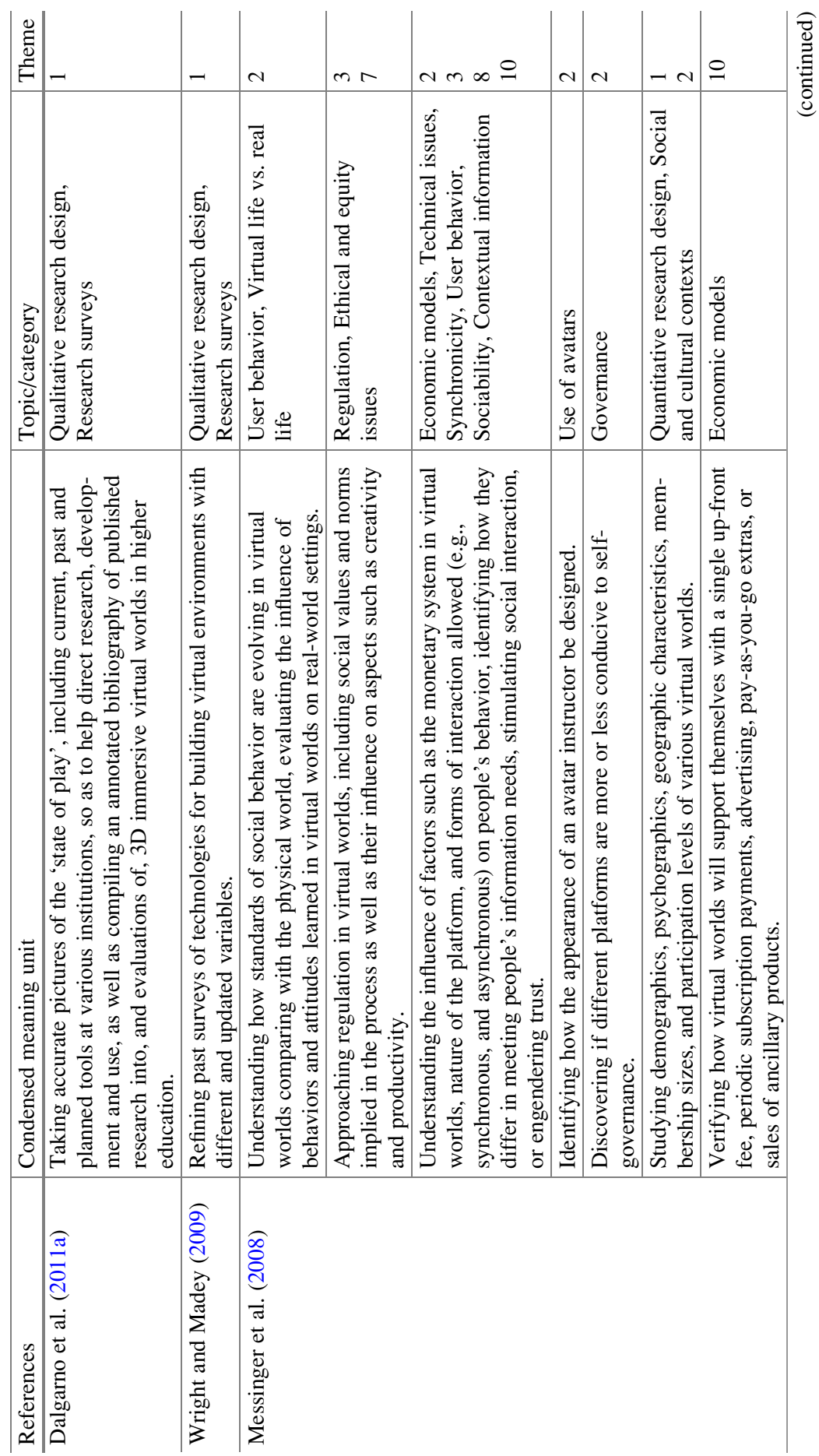


A. Correia et al.

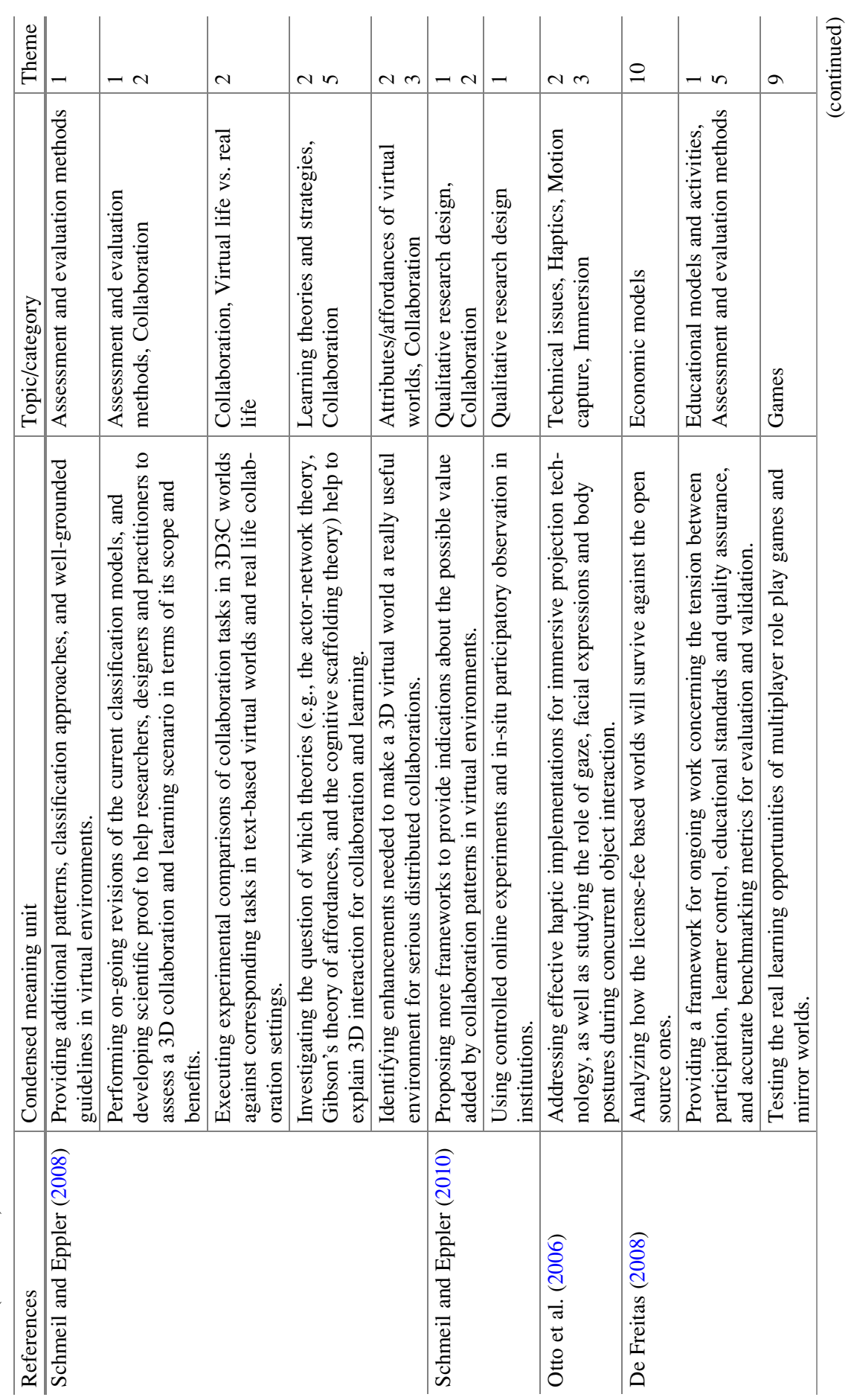




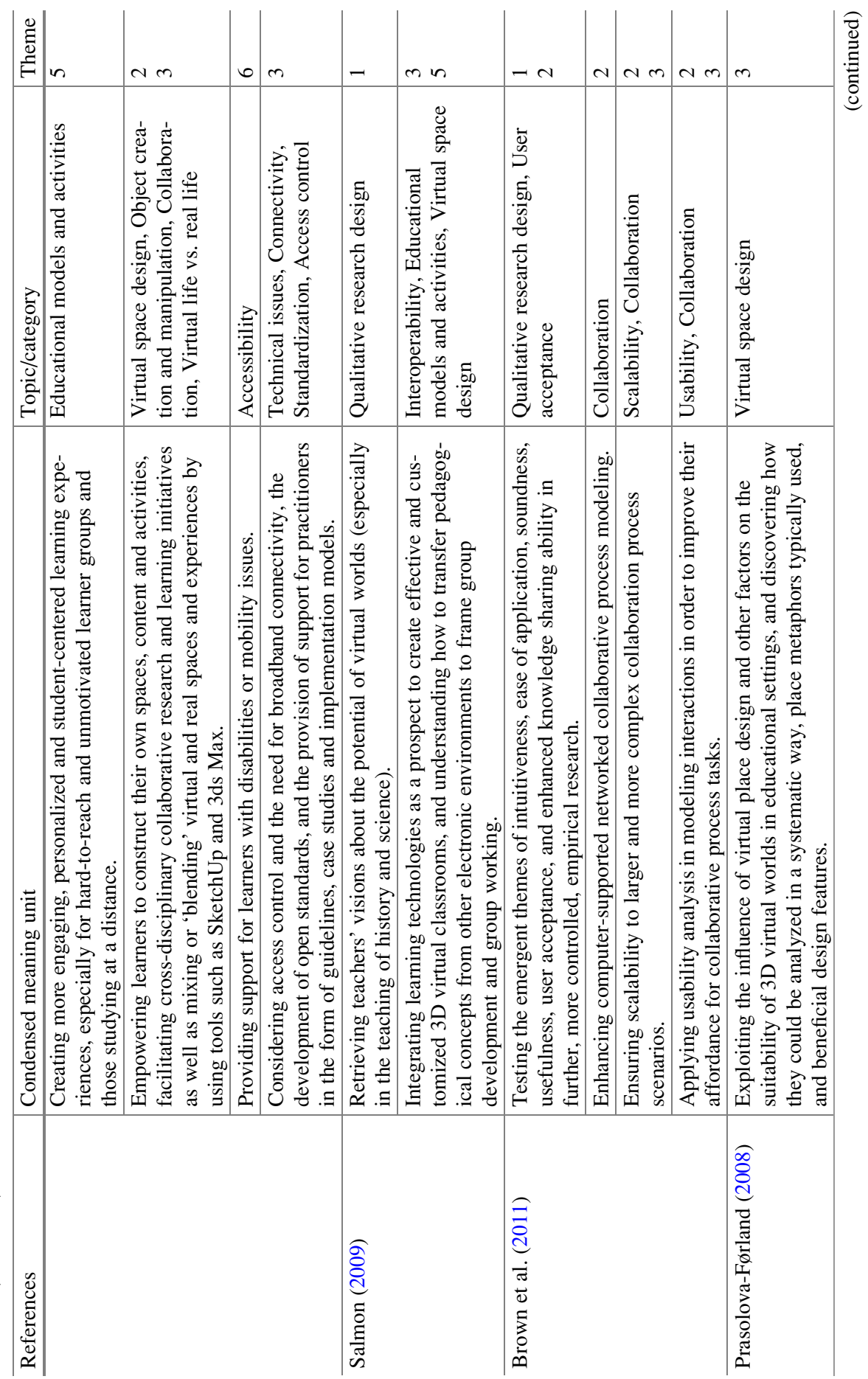



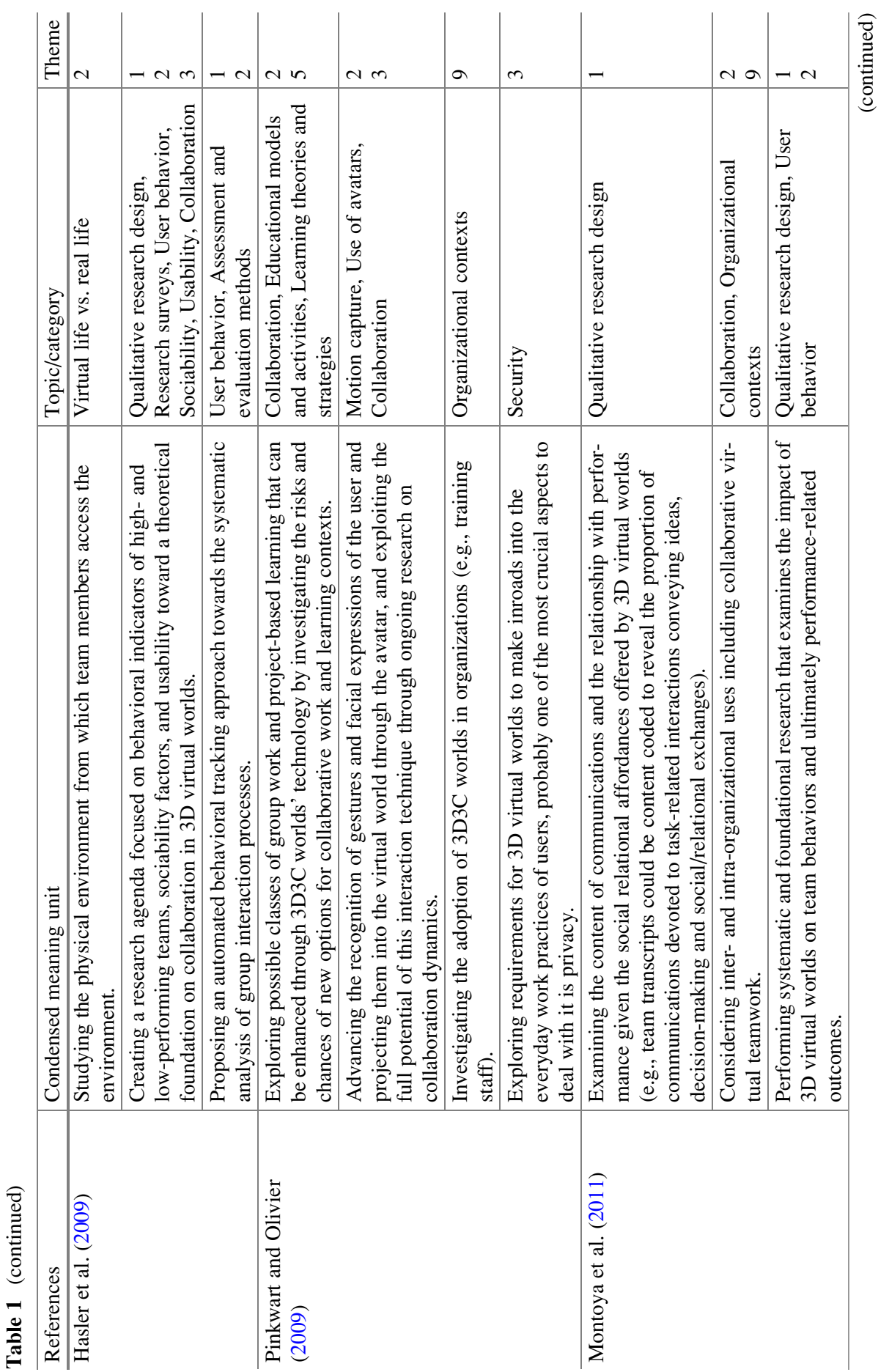


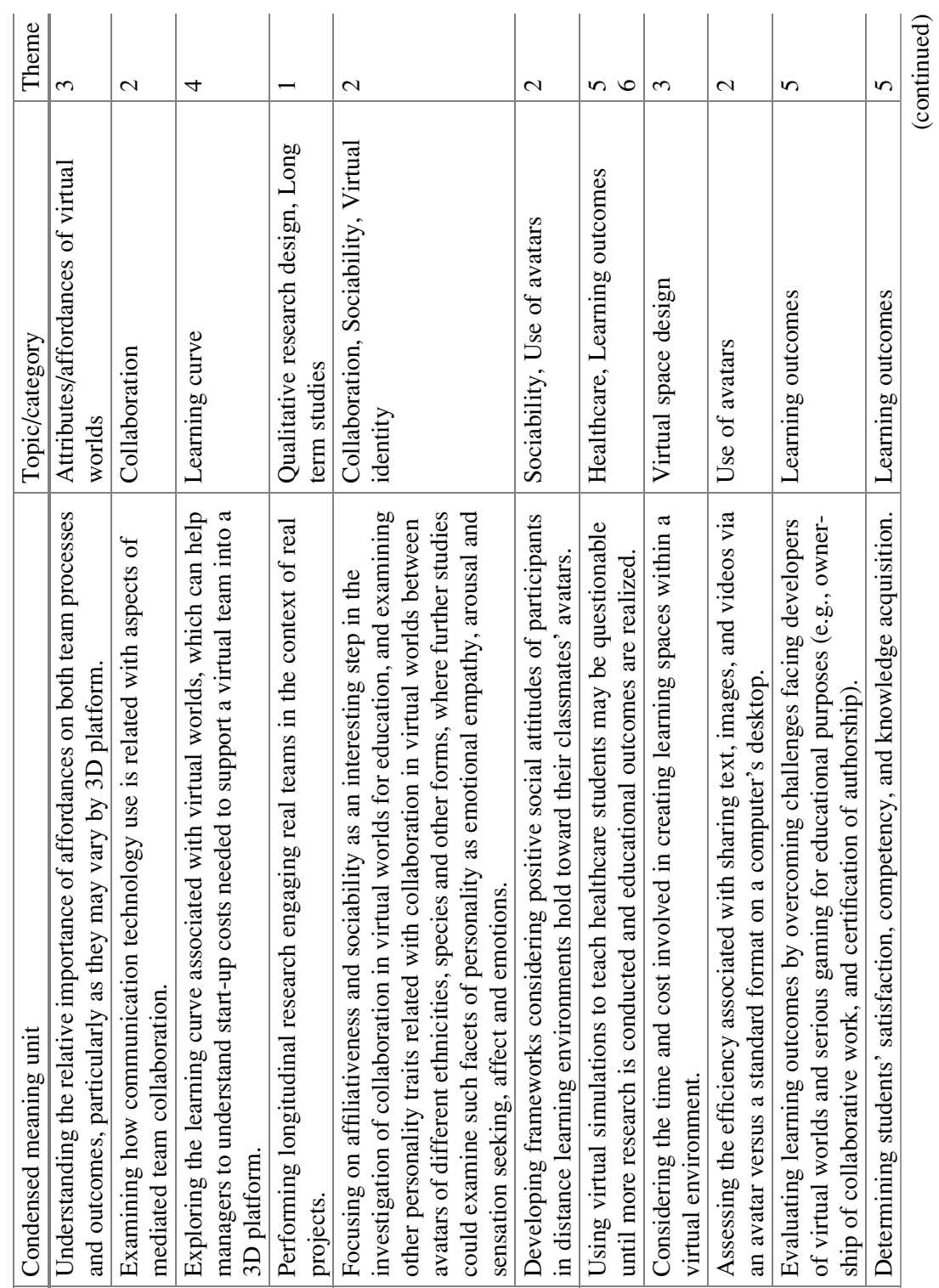




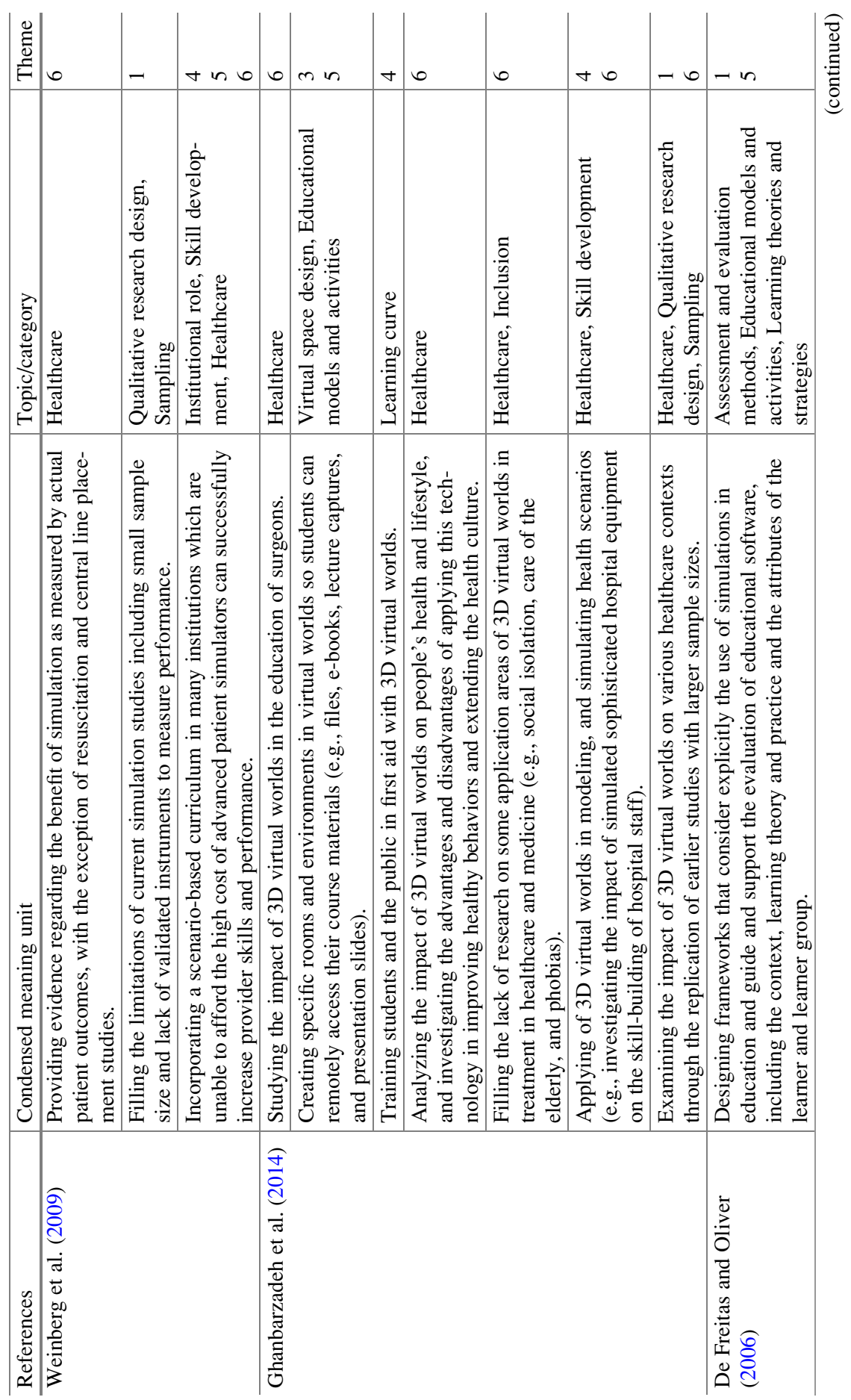




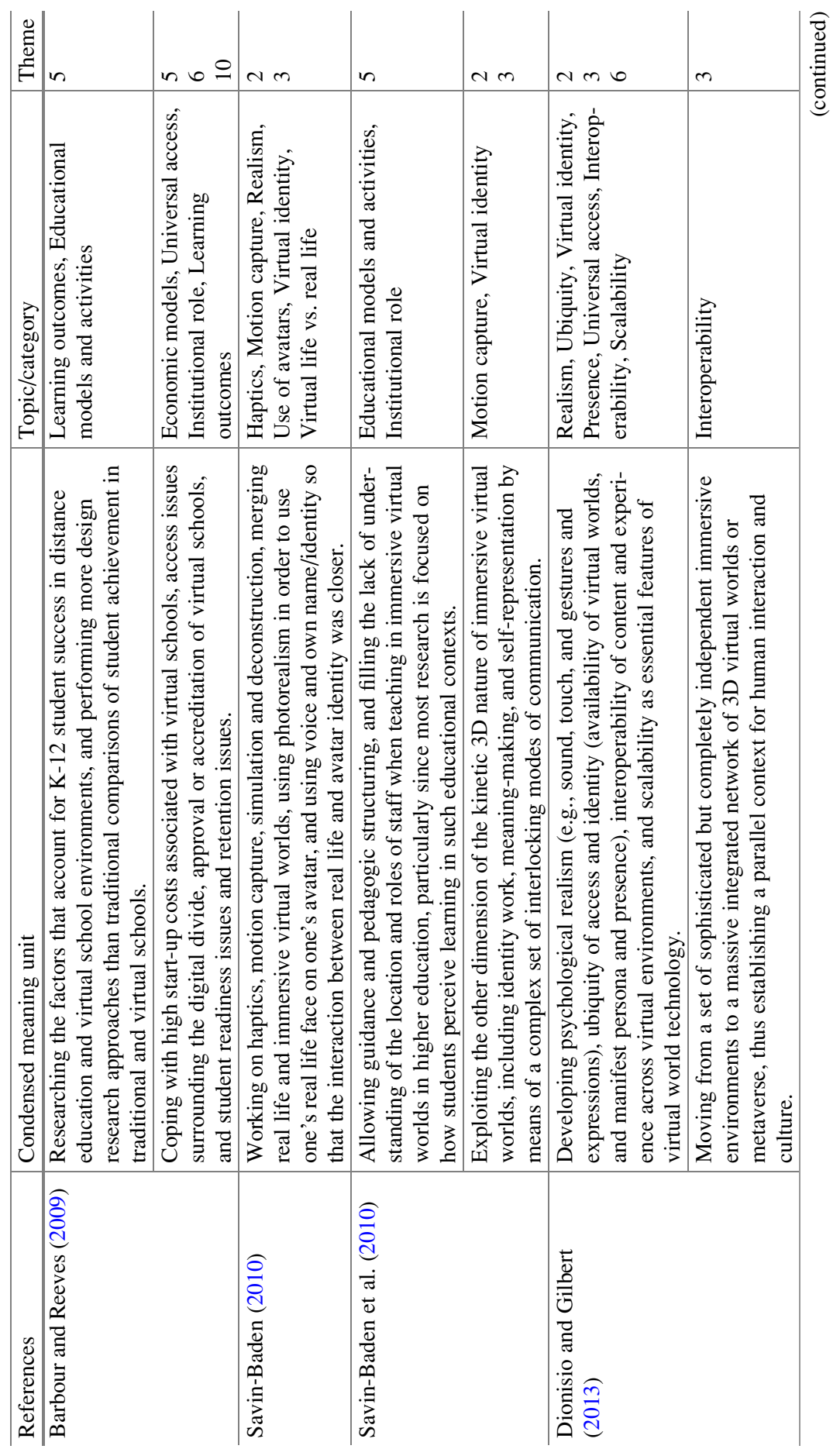




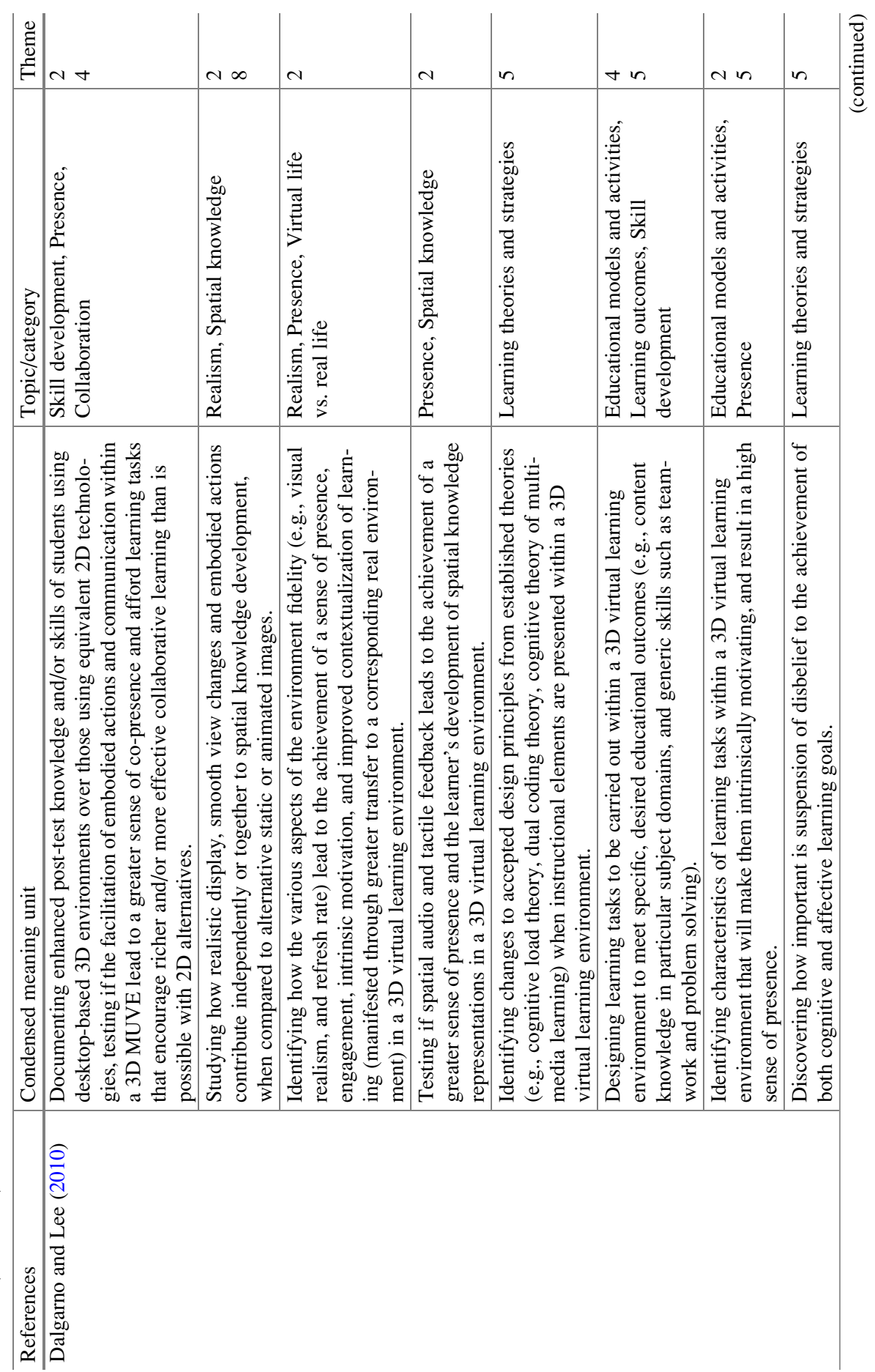




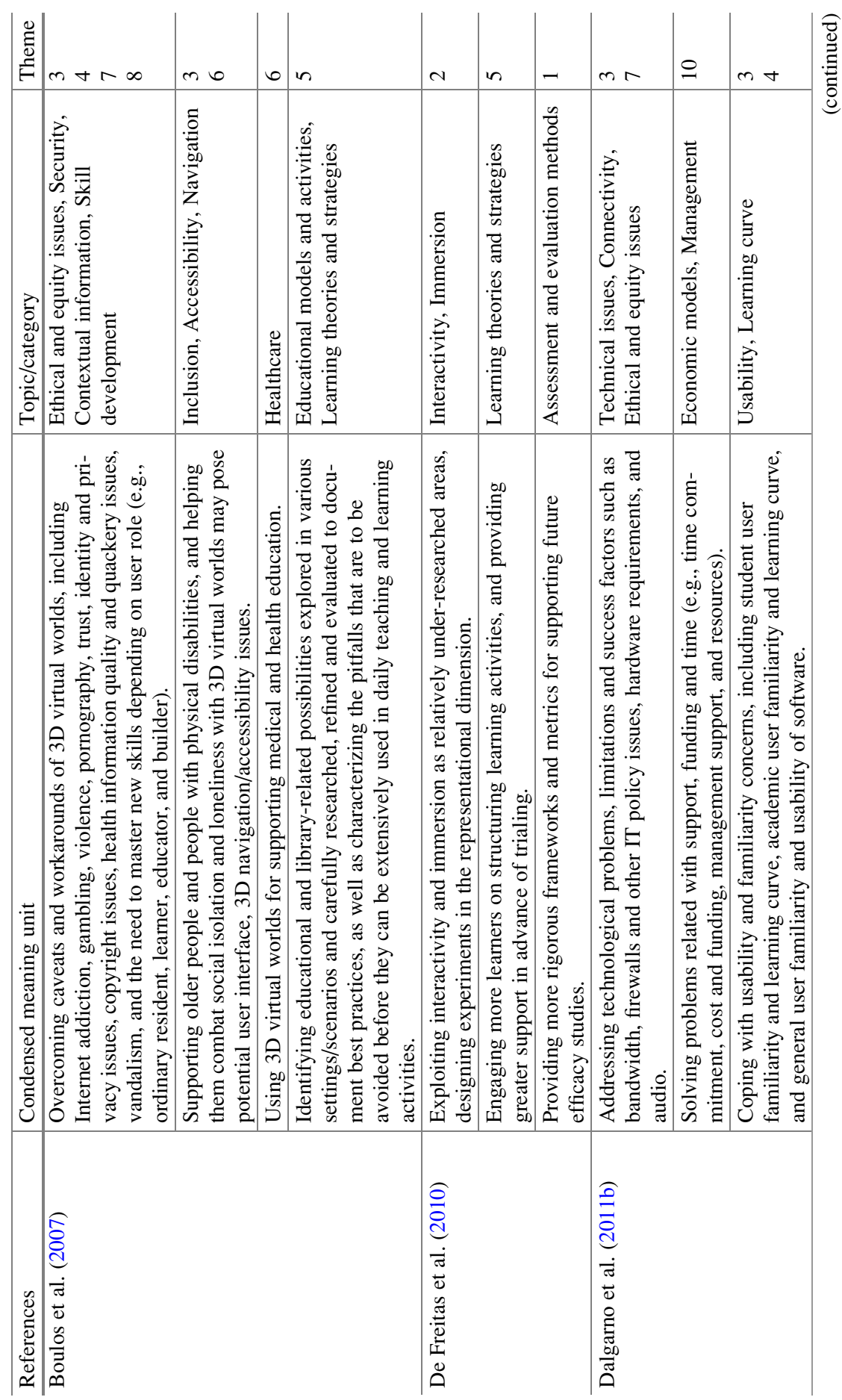




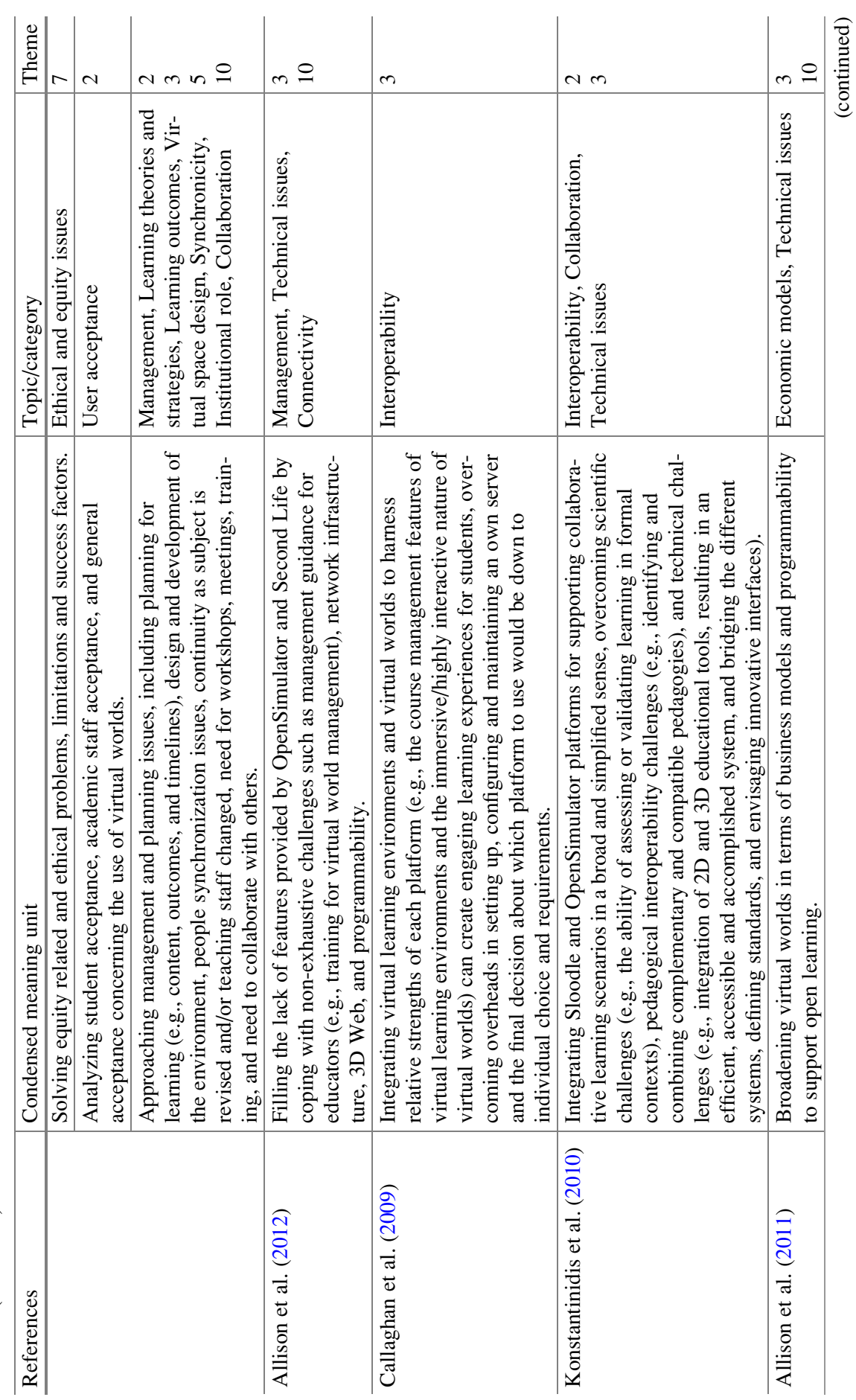




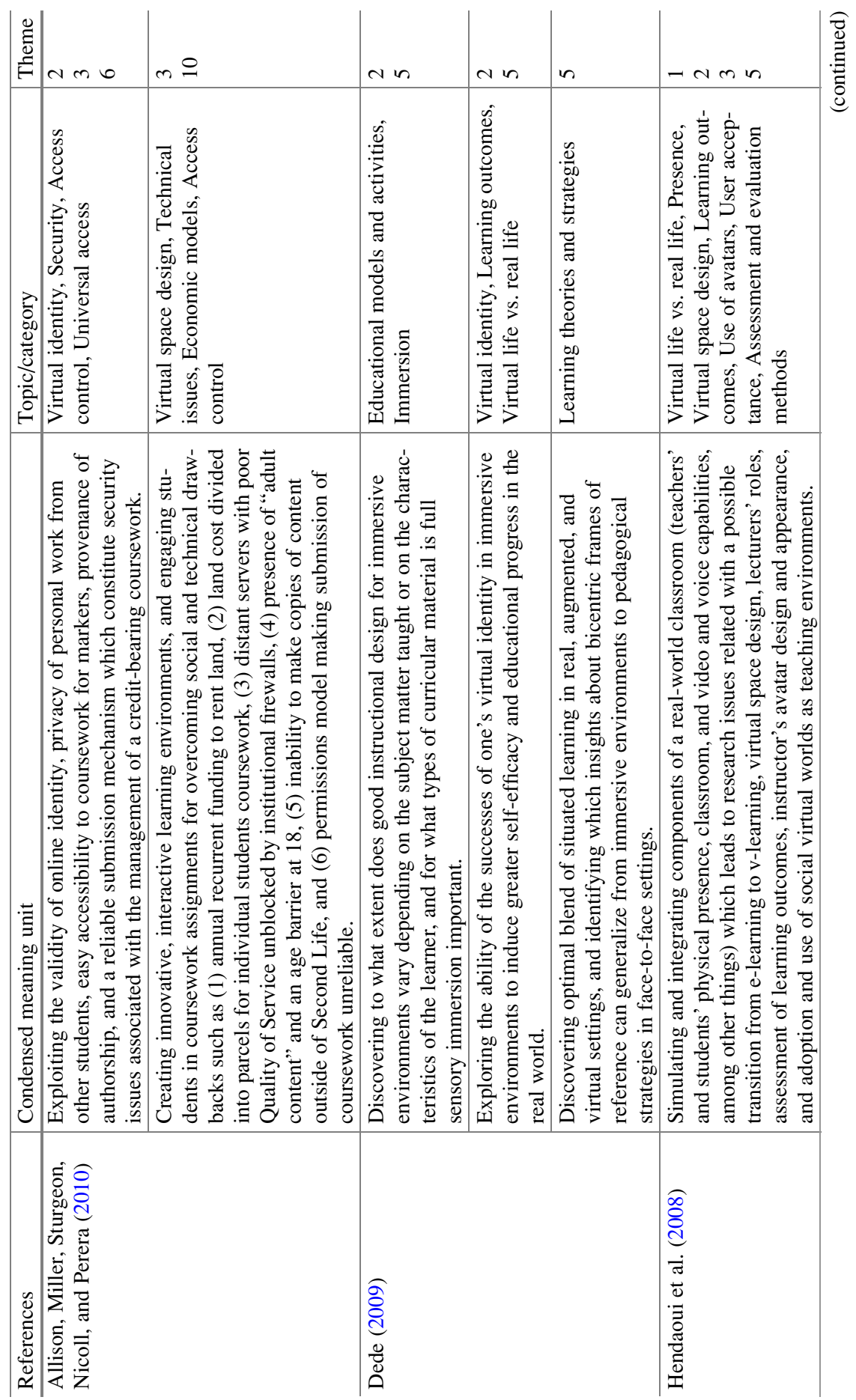



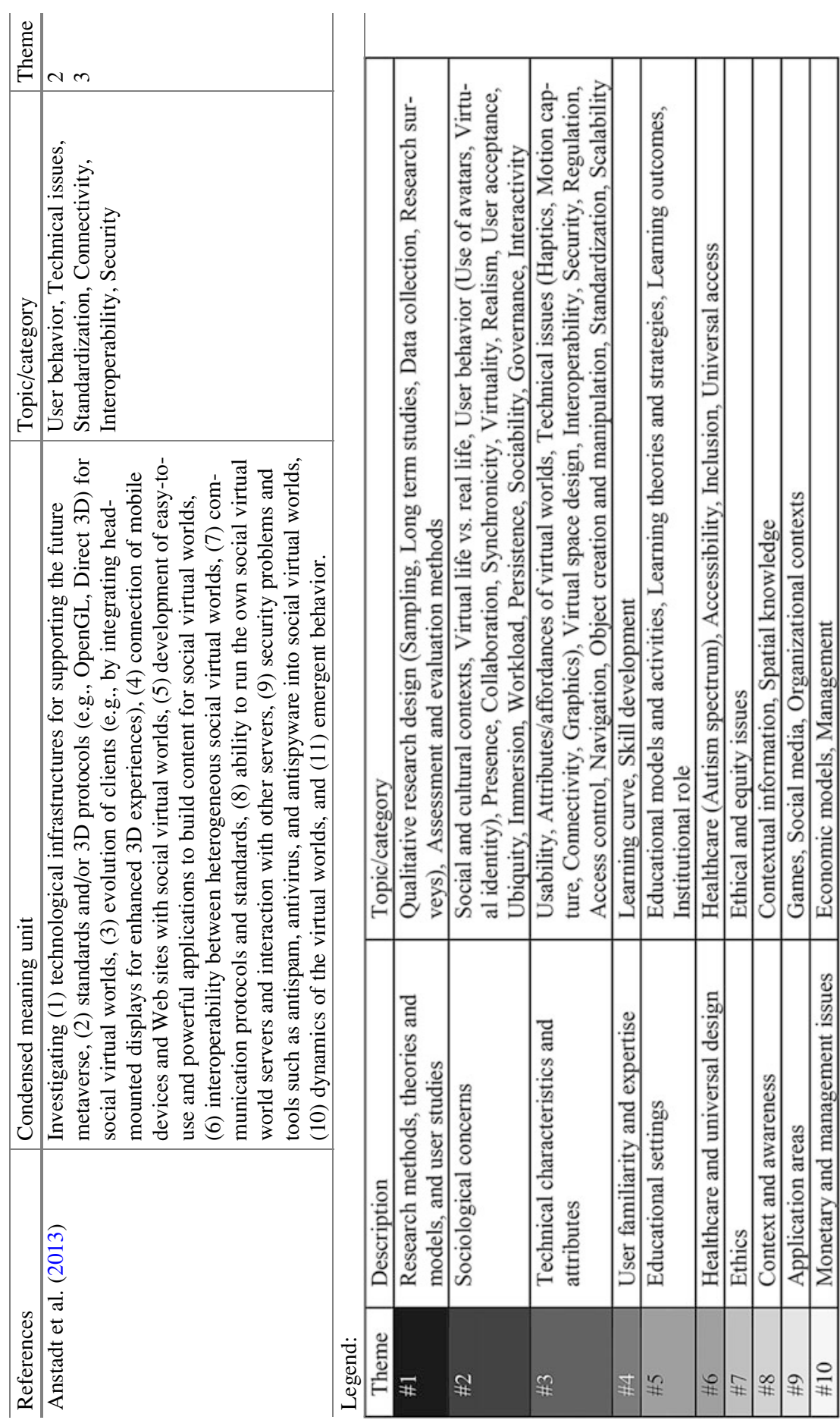
virtual environments). Complementarily, they also suggested the creation of more safe and secure environments for students in K-12, and the use of ethnography to collect and analyze data. Hence, a review undertaken by Savin-Baden et al. (2010) emphasized pedagogy, staff role, and digital literacies. The authors described issues concerned with identity work, meaning-making, self-representation, and location and roles of staff when teaching.

Savin-Baden's (2010) study on staff experiences of learning and teaching in immersive worlds "introduced issues relating to identity play, the relationship between pedagogy and play and the ways in which learning, play and fun were managed (or not)". The interaction between virtual world and real life was also addressed with challenges in haptics, motion capture, simulation and deconstruction, photorealism, and identity. Nevertheless, socio-political impacts of virtual world learning on higher education were exploited by Wimpenny et al. (2012), and three dominant frames of reference have appeared: institutional space and ownership, disciplinary learning, and games and gaming media. Moreover, a scoping guide for serious virtual worlds (De Freitas, 2008) discussed challenges related with the survivability of license-fee based worlds against open source platforms, the co-construction of virtual spaces, activities and content, the support for learners with disabilities or mobility limitations, and the creation of accurate benchmarking metrics for assessment and validation.

The use of virtual worlds in education was also studied from an OpenSimulator perspective (Allison et al., 2012), introducing challenges concerned with network infrastructure, management guidance, 3D Web, and programmability. Although 3D virtual learning environments are able to support teaching and learning in educational contexts, their presentation layer are highly restrictive (Callaghan et al., 2009), and more alternatives integrating virtual worlds with virtual learning environments (e.g., Sloodle) are required to create engaging learning experiences for students (Konstantinidis et al., 2010). Nonetheless, simulating and integrating the components of real-world classrooms, as well as adopting and using social virtual worlds as teaching environments were indicated as research goals (Hendaoui et al., 2008). The abilities of virtual worlds for engaging students in open learning were tested by Allison et al. (2011), despite their restrictiveness in terms of business models and programmability, while land cost, quality of server providers, age filter, authorship and privacy were also considered as challenges that must be addressed (Allison et al., 2010). As technology evolve to support learning specificities, more studies are needed regarding the abilities, strengths and preferences of immersive media, as well as the suitability of instructional designs to varied types of immersive mediums (Dede, 2009).

\subsection{Sociological Perspectives on 3D3C Worlds in Learning}

The seminal ethnographic work presented by Castronova (2001) dawned the interest on the use of qualitative data collection methods for virtual worlds research, 
considering interactivity, physicality, and persistence as distinguishing features. Subsequently, Castronova and Falk (2008) approached virtual worlds as Petri dishes for the social and behavioral sciences. A typology of virtual worlds was presented by Messinger et al. (2008), including the purpose, place, platform, population, and profit model. According to the authors, emergent features may become worth incorporating into such kinds of classification schemes. Furthermore, more research is needed on understanding standards of social behavior, attitudes learned in virtual worlds, influence of factors such as the nature of platform on people's behavior, regulation (e.g., social values and norms), avatar appearance, self-governance, etc. Nonetheless, economic concerns (e.g., periodic subscription payments), guidelines and demographics might also be studied. Anstadt et al. (2011) recognized a need for considering users with developmental and physical disabilities, the relationship between virtual and real life contexts, institutional roles, and ethical demands of practice (e.g., safety, and prevention). In addition, Bailenson and Yee (2008) mentioned the use of haptic devices as possible instruments to measure implicit attitudes towards aspects such as ethnicities or skin tones, while immersive 3D virtual worlds were addressed by Otto et al. (2006) taking into account their suitability for supporting closely coupled collaboration.

Davis et al. (2009) characterized the use of virtual worlds for virtual team collaboration, considering the virtual world itself, people/avatars, technology capabilities (communication, rendering, interaction, and team process), behaviors (coordination, trust, role clarity, and shared understanding), and outcomes (perceived quality, member support, self-image, cultural synchronicity, intent to immerse, deception, and reconnect anxiety) as elements of a conceptual model for virtual worlds research. The transition of newly acquired skills from virtual to real world and the impact of virtual reality on the neural network sustaining social abilities were indicated as current challenges. Some scholars believe that there is a need to cope with virtual identities, digital and cultural literacies, immersion, empathy and learning, design skills, collaboration, economic concerns (e.g., cost of purchasing land), social presence and social networks, standardization, and scaffolding persistence and social discovery (Warburton, 2009). Similarly, interactivity and immersion were also considered under-researched areas in the representational dimension (De Freitas et al., 2010).

A systematic description structure of collaboration patterns in 3D virtual environments was proposed by Schmeil and Eppler (2008), including usage situations, objective, number of participants, interaction intensity, typical duration, required artifacts, avatar actions, risks, and design effort. The authors advocate the promotion of new frameworks and on-going revisions in classification models, experimental comparisons of collaboration tasks in 3D virtual worlds, text-based virtual worlds, and real life collaboration settings, as well as theories explaining 3D interaction in collaboration and learning scenarios. Complementarily, Schmeil and Eppler (2010) suggested a systematic framework which "organizes the necessary elements for the design and implementation of collaboration patterns in virtual worlds", claiming for contributions on the use of controlled on-line experiments and in-situ participatory observation within organizations. Computer-supported 
networked collaborative process modeling was considered by Brown et al. (2011) as a challenge for researchers in terms of testing emergent themes (e.g., intuitiveness, user acceptance, and ease of application), ensuring scalability to larger and more complex collaboration process scenarios while applying usability analysis in modeling interactions.

Place metaphors used in 3D virtual learning environments were previously addressed (Prasolova-Førland, 2008). Hasler et al.'s (2009) conceptual framework and research agenda focused on behavioral indicators of virtual teamwork (i.e., form and content of team interaction, individual level effects, and intra- and intergroup effects), sociability factors (perceived presence, social conventions, emerging roles, and relationship formation), and usability factors (perceived usability, collaboration tools, communication mode, and support facilities). The link between spatial and visual characteristics, collaborative behaviors, and virtual teamwork in 3D3C worlds was explored by Montoya et al. (2011), while Wallace et al. (2009) studied the self-representation with human and non-human avatars concerning the willingness to collaborate in virtual worlds.

\subsection{Immersive Virtual 3D Healthcare Learning Environments}

Considering the application of 3D virtual worlds in healthcare, Phillips and Berge (2009) reported the use of teledentistry regarding insurance coverage, licensure, malpractice, and privacy. Creutzfeldt et al. (2010) claimed for solving technical troubles (e.g., bandwidth, downtime, and lag) and usage problems such as navigation, object creation and handling, and avatar manipulation. A literature review on three-dimensional healthcare learning environments (Hansen, 2008) suggested a need for empirical research about the pedagogical outcomes and advantages of this technology taking into account the time and cost involved in creating appropriate learning spaces within a $3 \mathrm{D}$ virtual environment. The use of simulation as a training and assessment tool in medical education (e.g., lethal events in pediatrics such as trauma and respiratory arrest) was approached by Weinberg et al. (2009) in the form of challenges and features for human patient simulators, including but not limited to monitoring blood pressure and programmable clinical scenarios.

An analysis on the use of 3D virtual environments in healthcare (Ghanbarzadeh et al., 2014) provided insights about the need for studying the impact of this technology in the education of surgeons, improving healthy behaviors and filling the lack of research on application areas such as social isolation, care of the elderly, and phobias. In addition, Boulos et al. (2007) also indicated challenges in medical and health education, including Internet addiction, gambling, violence, identity, privacy, copyright, trust, and pornography. Parsons and Cobb (2011) presented some advantages and benefits of virtual reality in social and life skills training for children on the autism spectrum, providing evidence on the nature of representation 
and the lack of robust and usable technologies that can enhance real world educational contexts. Moreover, Bellani et al. (2011) also analyzed the use of virtual reality for habilitation in autism, helping caretakers and educators to enhance the daily life social behaviors of autists.

\subsection{Technical Barriers and Empirical Research on 3D Learning Ecosystems}

A comprehensive survey performed by Dionisio and Gilbert (2013) identified psychological realism, scalability, interoperability, identity, and ubiquity of access across virtual environments as central features of virtual world technology. A vast number of limitations related with technology (e.g., bandwidth, audio, and IT policies), time commitment, cost and funding, usability, learning curve, ethics, management support and user acceptance were discussed by Dalgarno et al. (2011a, 2011b) Finally, technological infrastructures for metaverses, standards and 3D protocols, connection of mobile devices and websites with social virtual worlds, security, and interoperability were considered by Anstadt et al. (2013). Ubiquitous tracking and augmented reality have been arising as lines of further examination, while platforms such as $\mathrm{Xj3D}$ can be used to build and deploy 3D3C worlds. This breadth reinforces the view that an integration with collaboration tools allows increasing user's self-awareness, facilitating interaction and coordination while improving social bonds.

Qualitative methods such as ethnography and Grounded Theory are indicated as means of informing the creation of frameworks for classifying users, virtual worlds, collaboration mechanisms, and their relations in a systematic way (Jäkälä \& Pekkola, 2007). In addition, more research is needed about the past, current, and planned tools at various institutions by means of surveys and annotated bibliographies considering the use of 3D immersive virtual worlds in higher education (Wright \& Madey, 2009; Dalgarno et al., 2011a, 2011b). A lack of dedicated frameworks evaluating educational games and simulations in learning contexts and subject areas was mentioned as a limitation by De Freitas \& Oliver (2006). In addition, Pinkwart and Olivier (2009) indicated that "a cohesive body of research is still missing" taking into account the lack of empirical research on the risks and chances of 3D virtual worlds technology within collaborative settings, the system requirements, the connection between physical and virtual objects enabling new forms of cooperation trough 'mixed reality', and the adoption of 3D3C worlds in organizations. 


\section{Discussion}

In spite of the larger number of studies, some indicators can be interpreted from a qualitative point of view. A prevalence of challenges and possibilities concerned with research study design is clearly noted, including a lack of details about the methodology, a common absence of control groups, a short length and coverage of current studies, and a need for fine-grained surveys. A second level of challenges includes the relationship between users' virtual and real lives, technical issues (e.g., bandwidth, downtime and lag, and haptics), and educational models and activities. Furthermore, collaboration is also a topic of intensive research, including issues such as object co-creation within a virtual world. Other relevant aspects include but are not limited to assessment and evaluation methods (e.g., classification models), virtual space design, user behaviors (e.g., use of avatars), interoperability, skill development, learning theories and strategies, learning outcomes, and healthcare (e.g., autism spectrum). A distinct level of abstraction comprises issues related with sociability (e.g., daily life social behaviors of autists), security, familiarity with virtual worlds, institutional role, ethics and equity, economics, accessibility, inclusion, and synchronicity. Figure 2 represents a scheme for synthesizing research challenges and opportunities in learning through the use of 3D3C worlds.

The selection criterion used for naming the categories/topics is adopted from Dalgarno et al. (2011a, 2011b), including the number of mentions as a limitation, barrier or opportunity for research. A total of 36 main categories and 23 complementary topics (with less than four mentions) were identified. As previously mentioned, earlier studies have also proposed conceptual models and research agendas in different forms. For example, Davis et al. (2009) presented a scheme for virtual worlds research comprising technology capabilities, people/avatars, behaviors, and outcomes. Relationships between categories are not comprised in this scheme.

Each category/topic has its own constituent attributes. For instance, synchronicity can be represented by synchronous or asynchronous interaction, and such sub-categories constitute the temporal dimension of a time-space matrix (Johansen, 1988). Other examples include user behavior (which can be represented by the study of emotions, attitudes, virtual identity, use of avatars, etc.) and collaboration (e.g., environment, process, support, and functions). Furthermore, sub-functions of topics such as collaboration (e.g., instant messaging, and actor presence monitoring) can arise from a new level of abstraction. However, such abstraction requires a lot of work distilling units of analysis from large amounts of text.

\subsection{Research Methods, Theories and Models}

There is a lack of studies examining students' and teachers' perceptions using $3 \mathrm{D}$ virtual worlds (including detrimental effects) over a long period of time 


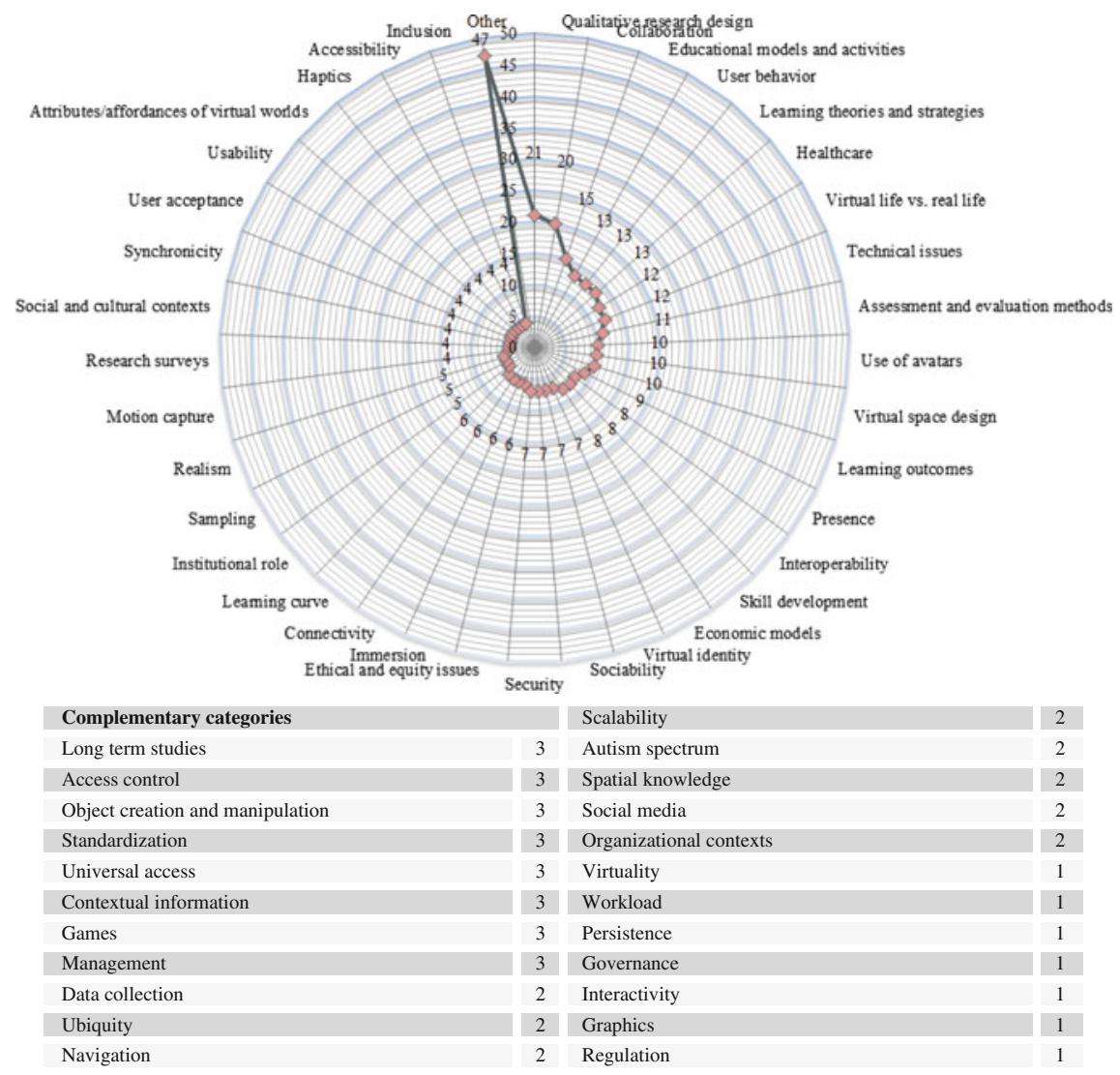

Fig. 2 Research challenges and possibilities on the use of 3D3C worlds in learning and training

(Hew \& Cheung, 2010). Furthermore, classification systems are required for characterizing new scenarios. Research agendas, annotated bibliographies, and surveys of published research are also required concerning the use and acceptance of 3D immersive virtual worlds in education settings (Wright \& Madey, 2009; Dalgarno et al., 2011a, 2011b). Data collection in 3D3C worlds is a current problem that can be addressed by using qualitative methods such as Grounded Theory (Jäkälä \& Pekkola, 2007) and virtual ethnography (Inman et al., 2010). Some experiments have been conducted "to evaluate the use of embodied survey bots (i.e., softwarecontrolled avatars) as a novel method for automated data collection in 3D virtual worlds" (Hasler et al., 2013). Replacing human interviewers by automated, survey bots in a virtual world involves ethical implications and needs the understanding of relations where humans might co-exist with automated entities. 


\subsection{Sociological Concerns}

While exploring the influence of self-representation on online perceptions using human and non-human 3D avatars is very important, including aspects such as androgyny, anthropomorphism, credibility, and skin tones (Bailenson \& Yee, 2008; Hew \& Cheung, 2010), more emphasis is needed on studying aspects such as in-world behavior, implicit attitudes and motivations, sociocultural factors affecting the use of 3D3C worlds, transitions between virtual life vs. real life, collaborative learning and cooperative work endeavors, and links between immersion, empathy, and learning. Researchers have recognized the importance of understanding and evaluating concepts such as presence, virtual identity and virtuality, realism (e.g., psychological), sociability, self-governance, and interactivity.

\subsection{Technical Characteristics and Attributes}

Issues related with interoperability between different virtual world platforms and other educational tools must be further addressed (Konstantinidis et al., 2010). As noted by Kelton (2008), there is a "lack of tools for facilitating truly collaborative interactions between users in real-time". Filling the lack of features provided by OpenSimulator and Second Life can be realized by coping with challenges such as programmability and network infrastructure (Allison et al., 2012), scalability (Dionisio \& Gilbert, 2013), and virtual space design (Hansen, 2008). Furthermore, working on 3D haptic implementations (e.g., video helmets), motion capture (e.g., Kinect), photorealism, simulation, and deconstruction (Otto et al., 2006; SavinBaden, 2010; Duncan et al., 2012) can allow a closer interaction between real-life and avatar identity.

\subsection{Educational Contexts}

The challenges related with $3 \mathrm{D}$ virtual learning environments include the perspective that "the only students typically successful in online learning environments are those who have independent orientations towards learning, highly motivated by intrinsic sources, and have strong time management, literacy, and technology skills" (Barbour \& Reeves, 2009). Learning analytics is another road of ongoing research (Duncan et al., 2012) for measuring the entire learning process and outcomes (Mikropoulos \& Natsis, 2011). Furthermore, there is a need for institutional support such as faculty development programs (Davis et al., 2009). Understanding the roles educational institutions play in online interaction and learning is also critical (Anstadt et al., 2011). Suitable learning theories and strategies for in-world 
course practice and design must be revised and examined more carefully (Duncan et al., 2012). Simulating and integrating components of real-world classrooms such as teachers' and students' physical presence (Hendaoui et al., 2008), identifying types of curricular material for which full sensory immersion is relevant (Dede, 2009), as well as characterizing the pitfalls that are to be avoided before they can be extensively used in daily teaching and learning activities (Boulos et al., 2007) must be also addressed by researchers interested in $3 \mathrm{D}$ virtual worlds.

\subsection{Healthcare and Accessibility}

The design of access technology for disabled people has presented several challenges concerned with solving real accessibility problems. Moreover, frameworks to evaluate, compare and classify such technology remain necessary since it is difficult to identify contributions, connections and gaps in this space (Bigham et al., 2011). Another set of significant contributions regards the study of virtual world education as an area of further development "for the physically and socially disadvantaged, which is lagging behind other areas of research" (Duncan et al., 2012). For example, 3D virtual spaces such as the virtual store of a supermarket can be constructed for allowing users navigate by products and ask for help using human computation features. Virtual worlds for education "should not disadvantage particular social, minority or disabled groups" and must be inclusive (Duncan et al., 2012). Social isolation is a current problem and elderly people can be engaged through several activities (e.g., physical exercise) using 3D virtual worlds and motion capture technology (Paredes et al., 2014). Digital divide is a reality in certain contexts and 3D virtual learning environments should be available to all students for getting easy access to coursework materials and submission of contributions (Allison et al., 2010). Nevertheless, autism spectrum (Bellani et al., 2011; Parsons \& Cobb, 2011), recovery treatments for traumas (e.g., military), and phobias (Ghanbarzadeh et al., 2014) are some application areas of 3D virtual worlds in healthcare and medicine.

\subsection{Additional Themes Concerned with 3D3C Worlds in Learning and Training}

Complementary categories covered in this study include user familiarity and expertise, ethics, context and awareness, monetary and management issues, and application areas. From a multidisciplinary point of view, investigating the users' experiences of leisure and serious gaming technology for explicit medical training intents (Phillips \& Berge, 2009), social networking tools and functions 
(Warburton, 2009), and inter-and intra-organizational contexts (Montoya et al., 2011) are some application areas of virtual worlds. The learning curve related with the perceived utility and natural use of virtual world technology is also a topic of further improvement. Ethical concerns associated with gambling, copyright, violence and privacy deserve attention (Boulos et al., 2007), context, and awareness remain topics of interesting research (Dalgarno \& Lee, 2010). Broadening virtual worlds in terms of economic models (considering issues such as land cost) must be also taken seriously to support open learning using three-dimensional spaces.

\section{Final Thoughts}

This chapter presents several challenges and possibilities for research in 3D virtual worlds in learning within an open, meta-theoretic research framework. The study carried on allowed identifying healthcare contexts, K-12 research, entertainment, security, cultural influence and immersion, economic concerns, mobile and multiplayer technologies, open source platforms, gestures recognition, social behaviors, and physical interaction. By updating work in the application areas of 3D virtual worlds, this study also attempts to help a wide variety of individuals and organizations, such as practitioners, nurses, managers, hospitals, healthcare agencies, private groups, business health companies and corporations, and universities (Ghanbarzadeh et al., 2014). Such insights can be particularly useful for researchers interested in this topic to better understand the field and previous studies, helping them classify research, identify gaps in the literature, and shape the future trends.

The results of this meta-analysis show that $3 \mathrm{D} 3 \mathrm{C}$ worlds find their place as alternative ecosystems to enhance learning and collaboration abilities between humans and computerized residents and objects. Heuristics, methods and interpretations of literature-based evidences are error prone and there is a need to reinforce the creation of research agendas and theoretical frameworks aware of the socialtechnical requirements of virtual worlds. In addition, this analysis needs future revisions and different perspectives on the current status of research in 3D3C worlds to reinforce an updated research basis focused on different disciplines.

Acknowledgments This work is funded (or part-funded) by the ERDF-European Regional Development Fund through the COMPETE Programme (operational programme for competitiveness) and by National Funds through the FCT-Fundação para a Ciência e a Tecnologia (Portuguese Foundation for Science and Technology) within project «FCOMP-01-0124-FEDER022701». The analysis and results presented in this study are entirely the authors' responsibility. Special acknowledgments are addressed to Tzafnat Shpak and Yesha Sivan for inviting the authors to submit this extended chapter as part of an ongoing research agenda on 3D virtual worlds for collaborative learning and cooperative work. 


\section{References}

Allison, C., Campbell, A., Davies, C. J., Dow, L., Kennedy, S., \& McCaffery, J. P., et al. (2012). Growing the use of virtual worlds in education: An OpenSim perspective. In Proceedings of the Second European Immersive Education Summit.

Allison, C., Miller, A., Sturgeon, T., Nicoll, J. R., \& Perera, I. (2010). Educationally enhanced virtual worlds. In IEEE frontiers in education conference (pp. T4F-1-T4F-6).

Allison, C., Miller, A., Sturgeon, T., Perera, I., \& McCaffrey, J. (2011). The third dimension in open learning. In Proceedings of the IEEE Frontiers in Education Conference (pp. T2E-1T2E-6).

Anstadt, S. P., Bradley, S., Burnette, A., \& Medley, L. L. (2013). Virtual worlds: Relationship between real life and experience in Second Life. The International Review of Research in Open and Distance Learning, 14(4), 160-190.

Anstadt, S. P., Burnette, A., \& Bradley, S. (2011). Towards a research agenda for social work practice in virtual worlds. Advances in Social Work, 12(2), 289-300.

Bailenson, J. N., \& Yee, N. (2008). Virtual interpersonal touch: Haptic interaction and copresence in collaborative virtual environments. Multimedia Tools and Applications, 37(1), 5-14.

Barbour, M. K., \& Reeves, T. C. (2009). The reality of virtual schools: A review of the literature. Computers and Education, 52(2), 402-416.

Bartle, R. A. (2010). From MUDs to MMORPGs: The history of virtual worlds. In J. Hunsinger et al. (Eds.), International handbook of internet research (pp. 23-39). Netherlands: Springer.

Bellani, M., Fornasari, L., Chittaro, L., \& Brambilla, P. (2011). Virtual reality in autism: State of the art. Epidemiology and Psychiatric Sciences, 20(3), 235-238.

Benford, S., Greenhalgh, C., Rodden, T., \& Pycock, J. (2001). Collaborative virtual environments. Communications of the ACM, 44(7), 79-85.

Bentley, R., Hughes, J. A., Randall, D., Rodden, T., Sawyer, P., \& Shapiro, D., et al. (1992). Ethnographically-informed systems design for air traffic control. In Proceedings of the ACM Conference on Computer-Supported Cooperative Work (pp. 123-129).

Bigham, J. P., Ladner, R. E., \& Borodin, Y. (2011). The design of human-powered access technology. In Proceedings of the International ACM SIGACCESS Conference on Computers and Accessibility (pp. 3-10).

Boulos, M. N. K., Hetherington, L., \& Wheeler, S. (2007). Second Life: An overview of the potential of 3-D virtual worlds in medical and health education. Health Information and Libraries Journal, 24(4), 233-245.

Brown, R., Recker, J., \& West, S. (2011). Using virtual worlds for collaborative business process modeling. Business Process Management Journal, 17(3), 546-564.

Callaghan, M. J., McCusker, K., Losada, J. L., Harkin, J., \& Wilson, S. (2009). Integrating virtual worlds \& virtual learning environments for online education. In Proceedings of the International IEEE Consumer Electronics Society's Games Innovations Conference (pp. 54-63).

Castronova, E. (2001). Virtual worlds: A first-hand account of market and society on the cyberian frontier (CESifo Working Paper No. 618).

Castronova, E., \& Falk, M. (2008). Virtual worlds as petri dishes for the social and behavioral sciences (German Council for Social and Economic Data No. 47).

Correia, A., Cassola, F., Azevedo, D., Pinheiro, A., Morgado, L., Martins, P., et al. (2014). Metatheoretic assumptions and bibliometric evidence assessment on 3-D virtual worlds as collaborative learning ecosystems. Journal of Virtual Worlds Research, 7(3), 1-18.

Crabtree, A., \& Rodden, T. (2008). Hybrid ecologies: Understanding cooperative interaction in emerging physical-digital environments. Personal and Ubiquitous Computing, 12(7), 481-493.

Creutzfeldt, J., Hedman, L., Medin, C., Heinrichs, W. L., \& Felländer-Tsai, L. (2010). Exploring virtual worlds for scenario-based repeated team training of cardiopulmonary resuscitation in medical students. Journal of Medical Internet Research, 12(3), e38. 
Dalgarno, B., \& Lee, M. J. (2010). What are the learning affordances of 3-D virtual environments? British Journal of Educational Technology, 41(1), 10-32.

Dalgarno, B., Lee, M. J., Carlson, L., Gregory, S., \& Tynan, B. (2011a). An Australian and New Zealand scoping study on the use of 3D immersive virtual worlds in higher education. Australasian Journal of Educational Technology, 27(1), 1-15.

Dalgarno, B., Lee, M. J., Carlson, L., Gregory, S., \& Tynan, B. (2011b). Institutional support for and barriers to the use of 3D immersive virtual worlds in higher education. In Proceedings of the 28th ASCILITE Annual Conference of the Australasian Society for Computers in Learning in Tertiary Education: Changing Demands, Changing Directions (pp. 316-330).

Damer, B. (2008). Meeting in the ether: A brief history of virtual worlds as a medium for usercreated events. Artifact, 2(2), 94-107.

Davis, A., Murphy, J., Owens, D., Khazanchi, D., \& Zigurs, I. (2009). Avatars, people, and virtual worlds: Foundations for research in metaverses. Journal of the Association for Information Systems, 10(2), 90-117.

De Freitas, S. (2008). Serious virtual worlds. A scoping guide. JISC e-Learning Programme. London: The Joint Information Systems Committee (JISC).

De Freitas, S., \& Oliver, M. (2006). How can exploratory learning with games and simulations within the curriculum be most effectively evaluated? Computers and Education, 46(3), 249-264.

De Freitas, S., Rebolledo-Mendez, G., Liarokapis, F., Magoulas, G., \& Poulovassilis, A. (2010). Learning as immersive experiences: Using the four-dimensional framework for designing and evaluating immersive learning experiences in a virtual world. British Journal of Educational Technology, 4l(1), 69-85.

Dede, C. (2009). Immersive interfaces for engagement and learning. Science, 323(5910), 66-69.

Dionisio, J. D. N., \& Gilbert, R. (2013). 3D virtual worlds and the metaverse: Current status and future possibilities. ACM Computing Surveys (CSUR), 45(3), 34.

Dodgson, M., Gann, D. M., \& Phillips, N. (2013). Organizational learning and the technology of foolishness: The case of virtual worlds at IBM. Organization Science, 24(5), 1358-1376.

Duncan, I., Miller, A., \& Jiang, S. (2012). A taxonomy of virtual worlds usage in education. British Journal of Educational Technology, 43(6), 949-964.

Fonseca, B., Paredes, H., Lt. Rafael, J., Morgado, L., \& Martins, P. (2011). A software architecture for collaborative training in virtual worlds: F-16 airplane engine maintenance collaboration and technology. In Proceedings of the 17th CRIWG Conference on Collaboration and Technology (pp. 102-109). Berlin, Heidelberg: Springer.

Ghanbarzadeh, R., Ghapanchi, A. H., Blumenstein, M., \& Talaei-Khoei, A. (2014). A decade of research on the use of three-dimensional virtual worlds in health care: A systematic literature review. Journal of Medical Internet Research, 16(2), e47.

Grady, S. M. (1998). Virtual reality: Computers mimic the physical world. New York, NY: Universities Press.

Graneheim, U. H., \& Lundman, B. (2004). Qualitative content analysis in nursing research: Concepts, procedures and measures to achieve trustworthiness. Nurse Education Today, 24(2), 105-112.

Grimstead, I. J., Walker, D. W., \& Avis, N. J. (2005). Collaborative visualization: A review and taxonomy. In Proceedings of the Ninth IEEE International Symposium on Distributed Simulation and Real-Time Applications (pp. 61-69).

Hansen, M. M. (2008). Versatile, immersive, creative and dynamic virtual 3-D healthcare learning environments: A review of the literature. Journal of Medical Internet Research, 10(3), e26.

Hasler, B. S., Buecheler, T., \& Pfeifer, R. (2009). Collaborative work in 3D virtual environments: A research agenda and operational framework. In A. A. Ozok \& P. Zaphiris (Eds.), Online communities and social computing (pp. 23-32). Berlin, Heidelberg: Springer.

Hasler, B. S., Tuchman, P., \& Friedman, D. (2013). Virtual research assistants: Replacing human interviewers by automated avatars in virtual worlds. Computers in Human Behavior, 29(4), $1608-1616$. 
Haynes, C., \& Holmevik, J. R. (1998). High wired: On the design, use, and theory of educational MOOs. Ann Arbor: University of Michigan Press.

Hendaoui, A., Limayem, M., \& Thompson, C. W. (2008). 3D social virtual worlds: research issues and challenges. IEEE Internet Computing, 12(1), 88-92.

Hew, K. F., \& Cheung, W. S. (2010). Use of three-dimensional (3-D) immersive virtual worlds in K-12 and higher education settings: A review of the research. British Journal of Educational Technology, 4l(1), 33-55.

Inman, C., Wright, V. H., \& Hartman, J. A. (2010). Use of Second Life in K-12 and higher education: A review of research. Journal of Interactive Online Learning, 9(1), 44-63.

Jacovi, M., Soroka, V., Gilboa-Freedman, G., Ur, S., Shahar, E., \& Marmasse, N. (2006). The chasms of CSCW: A citation graph analysis of the CSCW conference. In Proceedings of the ACM Conference on Computer Supported Cooperative Work (pp. 289-298).

Jäkälä, M., \& Pekkola, S. (2007). From technology engineering to social engineering: 15 years of research on virtual worlds. ACM SIGMIS Database, 38(4), 11-16.

Jarmon, L., Traphagan, T., Mayrath, M., \& Trivedi, A. (2009). Virtual world teaching, experiential learning, and assessment: An interdisciplinary communication course in Second Life. Computers and Education, 53(1), 169-182.

Johansen, R. (1988). Groupware: Computer support for business teams. New York, London: The Free Press.

Jonassen, D. H. (2004). Handbook of research on educational communications and technology. New York, NY: Taylor \& Francis.

Joslin, C., Di Giacomo, T., \& Magnenat-Thalmann, N. (2004). Collaborative virtual environments: From birth to standardization. IEEE Communications Magazine, 42(4), 28-33.

Kelton, A. J. (2008). Virtual worlds? "outlook good”. EDUCAUSE Review, 43(5), 15-22.

Kitchenham, B., Brereton, O. P., Budgen, D., Turner, M., Bailey, J., \& Linkman, S. (2009). Systematic literature reviews in software engineering-a systematic literature review. Information and Software Technology, 51, 7-15.

Konstantinidis, A., Tsiatsos, T., Demetriadis, S., \& Pomportsis, A. (2010). Collaborative learning in OpenSim by utilizing Sloodle. In Proceedings of the Sixth IEEE Advanced International Conference on Telecommunications (pp. 90-95).

Krippendorff, K. (1980). Content analysis: An introduction to its methodology (The Sage Commtext Series). London: Sage Publications.

Mak, W. K., \& Palia, A. P. (2014). Educational perspective of collaborative virtual communication and multi-user virtual environments for business simulations. Developments in Business Simulation and Experiential Learning, 32, 200-207.

Messinger, P. R., Stroulia, E., \& Lyons, K. (2008). A typology of virtual worlds: Historical overview and future directions. Journal of Virtual Worlds Research, 1(1), 1-18.

Mikropoulos, T. A., \& Natsis, A. (2011). Educational virtual environments: A ten-year review of empirical research (1999-2009). Computers and Education, 56(3), 769-780.

Montoya, M. M., Massey, A. P., \& Lockwood, N. S. (2011). 3D collaborative virtual environments: Exploring the link between collaborative behaviors and team performance. Decision Sciences, 42(2), 451-476.

Morgado, L. (2013). Technology challenges of virtual worlds in education and training-research directions. In Proceedings of the IEEE International Conference on Games and Virtual Worlds for Serious Applications (pp. 1-5).

Morgado, L., Varajao, J., Coelho, D., Rodrigues, C., Sancin, C., \& Castello, V. (2010). The attributes and advantages of virtual worlds for real world training. The Journal of Virtual Worlds and Education, 1(1), 15-35.

Moscato, D. R., \& Boekman, D. M. (2014). Using 3-D virtual worlds as a platform for an experiential case study in information systems auditing. Communications of the IIMA, 10(1), 3.

Okutsu, M., DeLaurentis, D., Brophy, S., \& Lambert, J. (2013). Teaching an aerospace engineering design course via virtual worlds: a comparative assessment of learning outcomes. Computers and Education, 60(1), 288-298. 
Onwuegbuzie, A. J., Leech, N. L., \& Collins, K. M. (2012). Qualitative analysis techniques for the review of the literature. Qualitative Report, 17, 56.

Otto, O., Roberts, D., \& Wolff, R. (2006). A review on effective closely-coupled collaboration using immersive CVE's. In Proceedings of the ACM International Conference on Virtual Reality Continuum and Its Applications (pp. 145-154).

Paredes, H., Cassola, F., Morgado, L., Carvalho, F., Ala, S., \& Cardoso, F., et al. (2014). Exploring the usage of 3-D virtual worlds and kinect interaction in exergames with elderly. In Proceedings of the International Conference on Computers Helping People with Special Needs (pp. 297-300).

Parsons, S., \& Cobb, S. (2011). State-of-the-art of virtual reality technologies for children on the autism spectrum. European Journal of Special Needs Education, 26(3), 355-366.

Phillips, J., \& Berge, Z. L. (2009). Second life for dental education. Journal of Dental Education, 73(11), 1260-1264.

Pierzchała, D., Dyk, M., \& Szydłowski, A. (2011). Distributed military simulation augmented by computational collective intelligence. In P. Jędrzejowicz, N. T. Nguyen, \& K. Hoang (Eds.), Computational collective intelligence. Technologies and applications (pp. 399-408). Berlin, Heidelberg: Springer.

Pinkwart, N., \& Olivier, H. (2009). Cooperative virtual worlds - a viable eCollaboration pathway or merely a gaming trend? Electronic Markets, 19(4), 233-236.

Prasolova-Førland, E. (2008). Analyzing place metaphors in 3D educational collaborative virtual environments. Computers in Human Behavior, 24(2), 185-204.

Reeves, B., Malone, T. W., \& O’Driscoll, T. (2008). Leadership's online labs. Harvard Business Review, 86(5), 58.

Salmon, G. (2009). The future for (second) life and learning. British Journal of Educational Technology, 40(3), 526-538.

Savin-Baden, M. (2010). Changelings and shape shifters? Identity play and pedagogical positioning of staff in immersive virtual worlds. London Review of Education, 8(1), 25-38.

Savin-Baden, M., Gourlay, L., Tombs, C., Steils, N., Tombs, G., \& Mawer, M. (2010). Situating pedagogies, positions and practices in immersive virtual worlds. Educational Research, 52(2), $123-133$.

Schmeil, A., \& Eppler, M. J. (2008). Knowledge sharing and collaborative learning in Second Life: A classification of virtual 3D group interaction scripts. Journal of Universal Computer Science, 14(3), 665-677.

Schmeil, A., \& Eppler, M. J. (2010). Formalizing and promoting collaboration in 3D virtual environments - a blueprint for the creation of group interaction patterns. In Proceedings of the International ICST Conference on Facets of Virtual Conference (pp. 121-134). Berlin, Heidelberg: Springer.

Schneider, D., Moraes, K., Moreira de Souza, J., \& Esteves, M. G. P. (2012). CSCWD: Five characters in search of crowds. In Proceedings of the IEEE 16th International Conference on Computer Supported Cooperative Work in Design (CSCWD) (pp. 634-641).

Schroeder, R., Heldal, I., \& Tromp, J. (2006). The usability of collaborative virtual environments and methods for the analysis of interaction. Presence, 15(6), 655-667.

Sequeira, L. M., Morgado, L., \& Pires, E. J. (2014). Simplifying crowd automation in the virtual laboratory of archaeology. Procedia Technology, 13, 56-65.

Serino, S., Triberti, S., Villani, D., Cipresso, P., Gaggioli, A., \& Riva, G. (2014). Toward a validation of cyber-interventions for stress disorders based on stress inoculation training: a systematic review. Virtual Reality, 18(1), 73-87.

Siriaraya, P., Ang, C. S., \& Bobrowicz, A. (2014). Exploring the potential of virtual worlds in engaging older people and supporting healthy aging. Behaviour and Information Technology, 33(3), 283-294.

Stangl, B., Kastner, M., \& Polsterer, F. (2012). Social virtual worlds' success factors: Four studies' insights for the tourism supply and demand side. In Forty-Fifth IEEE Hawaii International Conference on System Science (HICSS) (pp. 993-1002). 
Stapić, Z., López, E. G., Cabot, A. G., \& Ortega, L. M. (2012). Performing systematic literature review in software engineering. In Proceedings of the Central European Conference on Information and Intelligent Systems (pp. 441-447).

Sung, H. Y., \& Hwang, G. J. (2013). A collaborative game-based learning approach to improving students' learning performance in science courses. Computers and Education, 63, 43-51.

Wallace, P., Presley, A. B., Adrian, A. M., Belden-Adams, K., Caton-Rosser, M., Sleep, D., et al. (2009). Avoidance and attraction in virtual worlds: The impact of affiliative tendency on collaboration. The International Journal of Technology, Knowledge and Society, 5(3), $119-126$.

Warburton, S. (2009). Second Life in higher education: assessing the potential for and the barriers to deploying virtual worlds in learning and teaching. British Journal of Educational Technology, 40(3), 414-426.

Weinberg, E. R., Auerbach, M. A., \& Shah, N. B. (2009). The use of simulation for pediatric training and assessment. Current Opinion in Pediatrics, 21(3), 282-287.

Wiecha, J., Heyden, R., Sternthal, E., \& Merialdi, M. (2010). Learning in a virtual world: Experience with using second life for medical education. Journal of Medical Internet Research, 12(1), e1.

Wimpenny, K., Savin-Baden, M., Mawer, M., Steils, N., \& Tombs, G. (2012). Unpacking frames of reference to inform the design of virtual world learning in higher education. Australasian Journal of Educational Technology, 28(3), 522-545.

Wright, T. E., \& Madey, G. (2009). A survey of technologies for building collaborative virtual environments. The International Journal of Virtual Reality, 8(1), 53-66. 